Amit Agarwal, Dominik Ziemke, Kai Nagel

\title{
Bicycle superhighway: An environmentally sustainable policy for urban transport
}

Journal article | Submitted manuscript (Preprint)

This version is available at https://doi.org/10.14279/depositonce-9175

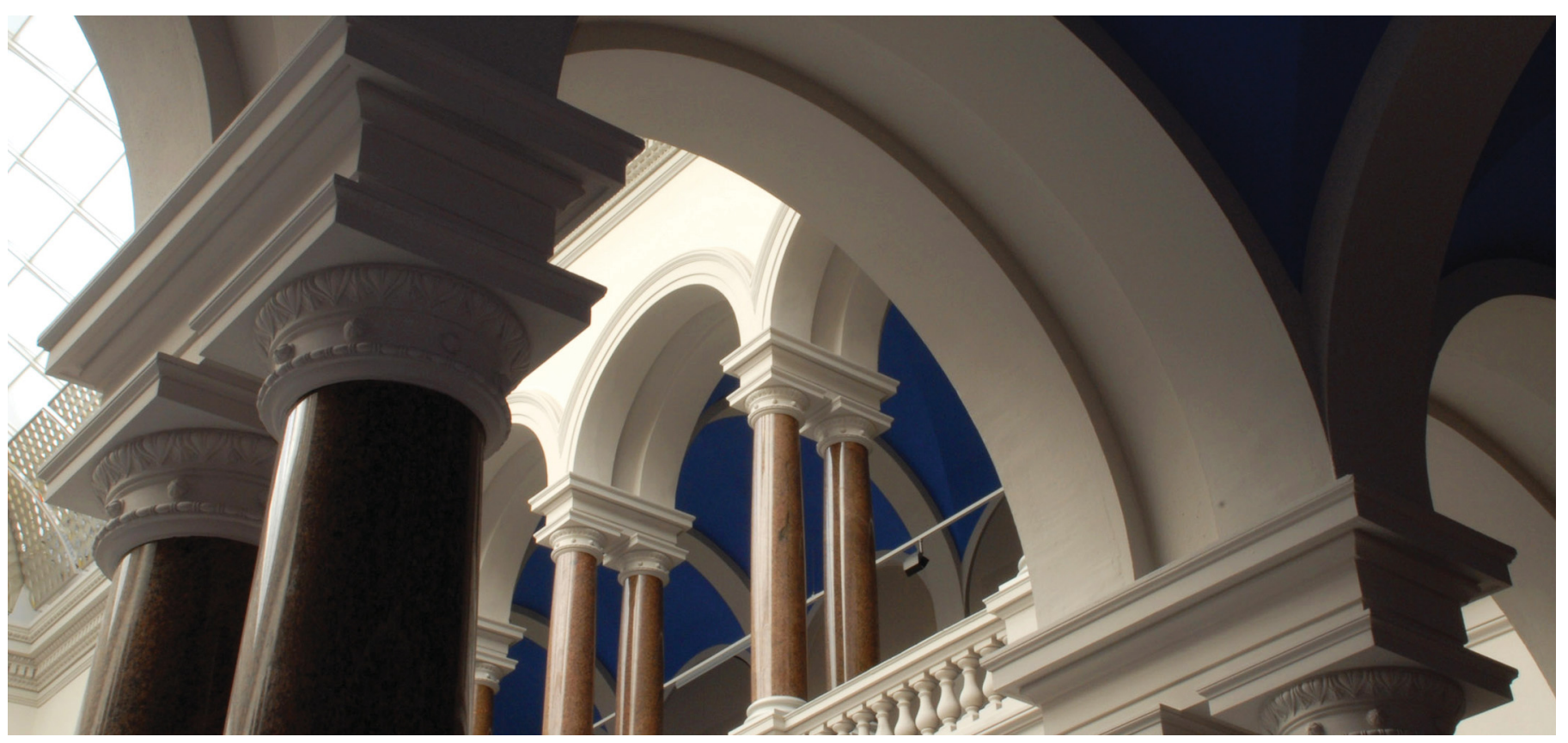

Agarwal, A., Ziemke, D., \& Nagel, K. (2019). Bicycle superhighway: An environmentally sustainable policy for urban transport. Transportation Research Part A: Policy and Practice. https://doi.org/10.1016/j.tra.2019.06.015 


\title{
Bicycle Superhighway: An Environmentally Sustainable Policy for Urban Transport
}

\author{
A. Agarwal*, D. Ziemke, K. Nagel \\ Technische Universität Berlin, Transport System Planning 83 Transport Telematics \\ Sekr. SG12, Salzufer 17-19, 10587 Berlin, Germany \\ Tel: +49-30-314-28308; Fax: +49-30-314-26269
}

\begin{abstract}
Bicycle is a sustainable low-carbon transport mode. However, insufficient or unplanned infrastructure leads to decrease in the share of bicycle in many cities of developing nations. In order to increase the bicycle share and to provide safer, faster and more direct routes, a bicycle superhighway is proposed for urban areas. This study identifies the potential of increase in the bicycle share. For maximum utilization of the new infrastructure, an algorithm is presented to identify the optimum number and locations of the connectors between proposed new infrastructure and existing network. Household income levels are incorporated into the decision making process of individual travellers for a better understanding of the modal shift. A real-world case study of Patna, India is chosen to show the application of the proposed superhighway. It is shown that for Patna, the bicycle share can escalate as high as $48 \%$ up from $32 \%$ by providing this kind of infrastructure. However, together with bicycles, allowing motorbikes on the superhighway limits the bicycle share to $44 \%$. The increase in bicycle share is mainly a result of people switching from motorbike, public transport and walk to the bicycle. Further, to evaluate the benefits of the bicycle superhighway, this study first extends an emission modelling tool to estimate the time-dependent, vehicle-specific emissions under mixed traffic conditions. Allowing only bicyclists on the superhighway improves congested urban areas, reduces emissions, and increases accessibility. However, allowing motorbikes on the superhighway increases emissions significantly in the central part of the urban area and reduces accessibilities by bicycle mode to education facilities which are undesirable. This study elicits that a physically segregated high-quality bicycle superhighway will not only attract current noncyclist travellers and increase the share of the bicycle mode, but will also reduce negative transport externalities significantly.
\end{abstract}

Keywords: Bicycle superhighway, sustainable transport, emissions, accessibility, mixed traffic, MATSim

\footnotetext{
*Corresponding author

Email addresses: agarwal@vsp.tu-berlin.de (A. Agarwal), ziemke@vsp.tu-berlin.de

(D. Ziemke), nagel@vsp.tu-berlin.de (K. Nagel)
} 


\section{Introduction}

\subsection{Urbanization}

The share of urban population has increased to $54 \%$ in 2014 up from $30 \%$ in 1930 and 4 it is expected to rise to $66 \%$ by 2050 (United Nations, 2014). This is accompanied by 5 an increase in the number of mega-cities (large urban agglomerations with more than 10 6 million inhabitants), which will increase from 10 to 41 in the period from 1990 to 2030 . 7 The spatial distribution of growth in urban population is uneven (Cohen, 2006; United Nations, 2014). For instance, approximately 90\% of the increase in urban population (between 2014 and 2050) is projected to be concentrated in Asia and Africa.

\subsection{Motorization, negative effects and economic losses}

Rapid urbanization is likely to increase the dependency on road transport and thus increase vehicle usage. Depending on possible government interventions for future policies, the total number of cars across the globe is expected to increase between 2.2 to 2.6 times from 2010 until 2050 (WEC, 2011). Faster urban spread and motorization in urban agglomerations is likely to increase the level of congestion, emissions, noise etc. which are major factors that hinder cities to develop in a more sustainable way.In congested traffic conditions, vehicle speeds reduce significantly and causes loss in time and fuel. Exhaust emissions is one of the major sources of air pollution releasing a variety of pollutants. Negative transport externalities such as congestion, emissions, accidents, noise etc. cause significant loss to the GDP (Gross Domestic Product) in terms of public health and economic growth (Gwilliam, 2002).

\subsection{Transport policies}

In decisions regarding transport policies, agencies decide a policy based on one or many factors such as the traffic patters, pressure on the supply, income levels of the households, modal share, objectives of the policy (e.g. generate revenues, abate transport externalities, etc.). An effective policy for a particular situation might not be effective in other situations because it is likely to differ with level of motorization, economic development, and urban form in each city. In reality, several urban transport policies are implemented to manage transport demand and/or supply based on different policy objectives. ${ }^{1}$ There is sufficient evidence in the literature which shows that the positive gains from real-world traffic restraint or pricing schemes are limited to the short term (Zhou et al., 2010; Cai and Xie, 2011; Beria, 2015; Percoco, 2014). In addition to this, a pricing scheme will be less effective if the share of potential toll payers (mainly car users in urban traffic) is very low.

In many cities of developing nations, low income households are captive to nonmotorized or to cheaper alternatives and a significant number of individual travellers cannot afford subsidised public transport (Badami and Haider, 2007; Tiwari et al., 2016). These persons are sometimes referred as the 'urban poor'. In cities with a significant share of households in low income groups, policies are very sensitive to household income levels, e.g. for travellers with low income, costs would be more important than travel time or comfort, whereas travellers with high income would prefer to travel with faster and more comfortable mode. In such scenarios, a possible measure would be to reserve a lane for those travellers who can pay the toll (Powell, 2001; Bar-Gera, 2012; Anderson and Geroliminis, 2015). A high toll on the reserved lane can restrict further possible switches from

\footnotetext{
${ }^{1}$ Please refer to Ch. 3 of Agarwal (2017) for an overview of different types of policy measures with related past studies.
} 
non-car (or non-motorized) to car (or motorized) trips and produce a balance between different user preferences (travel time/cost). Toll values in such cases, are typically set based on demand and supply.Such a policy would be effective in cases where the majority of urban roads have two or more lanes, which is, however, typically not the case in urban areas of many cities of developing nations, e.g. $36 \%$ of the total road length in Patna, India have a width of less than $5 m$ (TRIPP et al., 2009).

\subsection{Sustainable urban transport}

Concerns about the aforementioned issues related to fast increase in population and rapid urbanization are growing. Civic bodies are exploring sustainable low-carbon transport options and measures to increase non-motorized transport (NMT) modes (e.g. bicycle, walk). Apart from its established health benefits (Mueller et al., 2017), it is quoted as one of the most sustainable forms of transport due to its reliability, affordability and low or zero negative transport externalities (Gatersleben and Appleton, 2007). Rastogi (2011) recognises key issues and provide guidelines in favour of sustainable transport, where an emphasis is given to the promotion of walking and bicycle. Bicycle used to be a neglected field of study, but is gaining ground and becoming a more important transport mode. In order to increase the share of sustainable and low carbon transport modes, strong measures like a strengthening and integration of public transport and NMT infrastructure as well as improvements in fuel and vehicle technology are required. In absence of sufficient infrastructure for public transport (PT) and NMT, travellers, who can afford this, are shifting to private modes (e.g. car, motorbike). Interaction with motorized traffic increases the real and perceived danger, and discomfort for walking and bicycling which is likely to reduce the NMT share (Jacobsen et al., 2009). Similar reasons have led to decline in the share of walk and bicycle modes in many cities of India (Tiwari et al., 2016).

In the last few decades, emphasis of urban transport policies is put on the development of sustainable urban transport strategies such that the interests of future generations can be protected. According to Bugliarello (2006), for a city, the three important sustainable measures are: (a) to reduce the external environmental footprint, (b) to make city more livable in terms of transportation, housing, water etc. and (c) to make the suburbs more sustainable. Similarly, Goldman and Gorham (2006) identify four directions, which outline the potential visions of sustainable transport while major importance is given to innovative practice on ground. One of the directions is to make cities more livable while focusing on increasing accessibilities, efficient allocation of public space and improving overall health and economic welfare of residents etc. With an example of Bogotá, the authors highlight the strict provision of pathways for non-motorized transport modes through urban centres. Following such visions, the use of bicycle is promoted in different parts of the world via diverse policy initiatives to increase the share of the bicycle (Martens, 2007; Su et al., 2010; Buehler et al., 2016; Pucher and Buehler, 2008). Cyclists ${ }^{2}$ are sensitive to distance, turn frequency, slope, intersection control, traffic volume, traffic mix, travel time, on-street parking, roadway speed limit, discontinuities (Broach et al., 2012; Sener et al., 2009; Verma et al., 2016; Menghini et al., 2009; Hood et al., 2011). The comfort perception of the cyclists is also affected by age, type of two-wheeled vehicles, width of bicycle lane, roadside land-use etc. (Bai et al., 2017). Several studies have shown that

\footnotetext{
${ }^{2}$ Terms 'bicycle' and 'cycle' are common ways of addressing two-wheeler non-motorized vehicle. In the context of developing nations, the latter is more common. In this study, both terms are used interchangeably unless otherwise stated.
} 
improvement of various bicycle facilities is likely to increase the bicycle ridership (Martens, 2007; Wardman et al., 2007), trip length (Tilahun et al., 2007) and safety (McClintock and Cleary, 1996). The provision of bicycle lanes adjacent to the lanes for the motorized traffic is a common way of bicycle facilities in many parts of the world. In a study, it is shown that a bicycle lane offsets the negative effects of adjacent motorized traffic. It does, however, not offer any additional attractiveness than a low traffic volume local street (Broach et al., 2012). In addition to this, safety, comfort and the convenience of riding a bicycle are the top priorities for potential users who take these aspects more strongly into account than captive riders (Jain et al., 2010). Safety, comfort, convenience of cyclists are likely to increase with a physically segregated infrastructure and this, in turn, can play a vital role in promotion of sustainable urban transport.

\subsection{Physical segregation of bicycle lane}

Bai et al. (2017) show that physical segregation of bicycle lanes from motorized traffic and pedestrian lanes (footpath) significantly increase the comfort perception of cyclists. Given the scarcity of space in urban areas, it is possible that such bicycle lanes are somewhat longer and off-track. However, with the help of revealed preference surveys, it was shown that bicyclists adjust their routes to use off-street or off-track bicycle paths (Krizek et al., 2007; Howard and Burns, 2001; Broach et al., 2012). Bicyclists are also willing to take the longer route to use such bicycle lanes (Standen et al., 2017). In another study, it was found that these detours could be as high as $67 \%$ higher than shortest distance (Krizek et al., 2007). An off-track bicycle facility is also likely to increase the bicycle ridership (Tilahun et al., 2007). This will encourage the captive users as well as currently non-cyclists. The female bicycle ridership is very low in many developing nations (Tiwari et al., 2008), which is likely to rise with an off-track cycleway (Standen et al., 2017). Therefore, based on the foregoing discussion, this study analyses the importance of a bicycle superhighway ${ }^{3}$ for urban centres. The term 'superhighway' is used to distinguish this infrastructure from (regular) bicycle lanes. The aim is to provide safer, faster, direct and comfortable routes for bicycle riders rather than providing an infrastructure to move out non-motorized modes from motorized traffic lanes to make motorized traffic faster.

\subsection{Research gap}

The benefits from the new cycleway or superhighway in an urban area are understudied, particularly, in (a) quantifying the potential of increase in bicycle share, (b) assessing congestion, emissions levels in the urban area and (c) evaluating impacts on accessibilities due to new infrastructure. This study bridges these gaps with the help of a real-world case study. Thus, main key contributions of this study are:

- to integrate household income-levels in the utility function for policy evaluation

- to identify the potential for bicycle trips in an urban area

- to determine the optimal number and locations of connectors between new and existing streets and

- to assess the benefits of new bicycle infrastructure (e.g. emissions, accessibilities).

\footnotetext{
${ }^{3}$ Please refer to http://denmark.dk/en/green-living/bicycle-culture/cycle-super-highway and http: //lcc.org.uk/pages/cycle-superhighways for some practical examples.
} 
For this, a bicycle superhighway in the urban centre is proposed and the extent of the aforementioned benefits are quantified using an activity-based multi-agent transport simulation framework. For the application of a bicycle superhighway, a case study of Patna, India is chosen. Further, this study also proposes an innovative approach to find the optimal number and locations of the connectors between the new infrastructure and the existing network. To estimate the vehicle- and link-specific time-dependent emissions under mixed traffic conditions, an emission modelling tool (EMT; Kickhöfer et al., 2013) is extended. Moreover, using the case study, this work provides insights which are useful to encourage policy makers and law enforcement.

The remainder of the paper is organized as follows. Sec. 2 elaborates on the concept and methodology of bicycle superhighways and it's connectors to the existing network. The multi-agent transport simulation framework for the present study is briefly presented in Sec. 3. The application of bicycle superhighway is described in Sec. 4. This section also illustrates the simulation setup, an income-dependent utility function and policy scenarios. The results and findings are analysed in Sec. 5. The impact of the policies on the congestion, emissions and accessibilities are visualized spatially in this section. The potential for increase in bicycle share and sensitivity for the assumption related to riding bicycle on superhighway are provided in Sec. 6. The main findings of this study are summarised in Sec. 7 .

\section{Bicycle superhighway}

In London, a number of bicycle superhighways has been implemented over the last years (TfL, accessed Sep. 2017). Introduction of the new infrastructure has increased bicycle share mainly on direct, continuous routes and on routes with better cycling landscape (Law et al., 2014). In the context of developing economies such as India, the development of NMT is favourable because (i) a high share of travellers belongs to low or middle income households, (ii) the share of shorter trips is very high (Rahul and Verma, 2013). Thus, there is enough potential to increase the share of the bicycle mode as well as the walk mode, provided that an efficient infrastructure is available. Following this observation, this study recommends a bicycle superhighway for Panta, India and evaluates its impact in terms of modal share, congestion, emissions and accessibilities.

For Patna, the bicycle share is about 33\% (TRIPP et al., 2009), which underscores the need of a physically segregated infrastructure for bicycle modes. There are at least two major hurdles for constructing a bicycle superhighway in the urban area:(i) Lack of space is a common problem when constructing any kind of road infrastructure or widening of existing road infrastructure for a bicycle lane and/or a footpath. The situation can become severe if the required land is in built-up areas. Generally, the preferred way of constructing a bicycle superhighway is at level because of construction costs and ease of access of the infrastructure. However, in case space is scarce, a bicycle superhighway can also be build as an elevated track, potentially on top of other transport infrastructures. (ii) Restriction of motorbikes: Generally, a bicycle lane in India is about $2.5 \mathrm{~m}$ wide so that cycle-rickshaw ${ }^{4}$ drivers can also use them (Tiwari, 2001). A major drawback of this is that - due to wide bicycle lane and poor law enforcement - they are frequently also used by motorbike riders. This is likely to reduce the attractiveness for bicycle riders. A

\footnotetext{
${ }^{4}$ A cycle rickshaw is generally a three wheeler, non-motorized vehicle and used to move goods or passengers.
} 
similar situation can not be ruled out on the bicycle superhighways. These two issues are addressed later in Sec. 4.2.3 in the case study.

\subsection{Cost-benefit comparison}

Table 1: Comparison of various parameters between motorized highway and high quality bicycle lane. Source: Rastogi (2011).

\begin{tabular}{|c|c|c|}
\hline \multirow[b]{2}{*}{ Attribute } & \multicolumn{2}{|c|}{ Infrastructure for... } \\
\hline & motorized vehicle & bicycle \\
\hline Space requirement per person $\left[\mathrm{m}^{2}\right]$ & 120 & 9 \\
\hline Passenger capacity $[/ h \cdot / m]$ & $100-400$ & 1500 \\
\hline Cost of construction (ratio) $[-]$ & 20 & 1 \\
\hline Material requirement $[\mathrm{kg} /$ person $]$ & $1260-1440$ & 30 \\
\hline
\end{tabular}

Generally, the feasibility of a project or a new infrastructure is determined based on a cost-benefit analysis. While this is beyond the scope of the present study, a brief comparison with motorized highway based on several attributes is presented in this section to highlight the potential benefits of a bicycle superhighway. In Tab. 1, it can be observed that more passengers can be transported in less space using a bicycle infrastructure, which is also associated with lower investment costs compared to infrastructure for motorized traffic. In addition to this, the monetary benefits from reduction of congestion, air pollution, accident risk, vehicle operation cost etc. can amount to 250,000 INR per day if $1 \%$ of travellers switch their mode from motorized mode to non-motorized mode in Bangalore city (Rahul and Verma, 2013).

\subsection{Bicycle superhighway connectors}

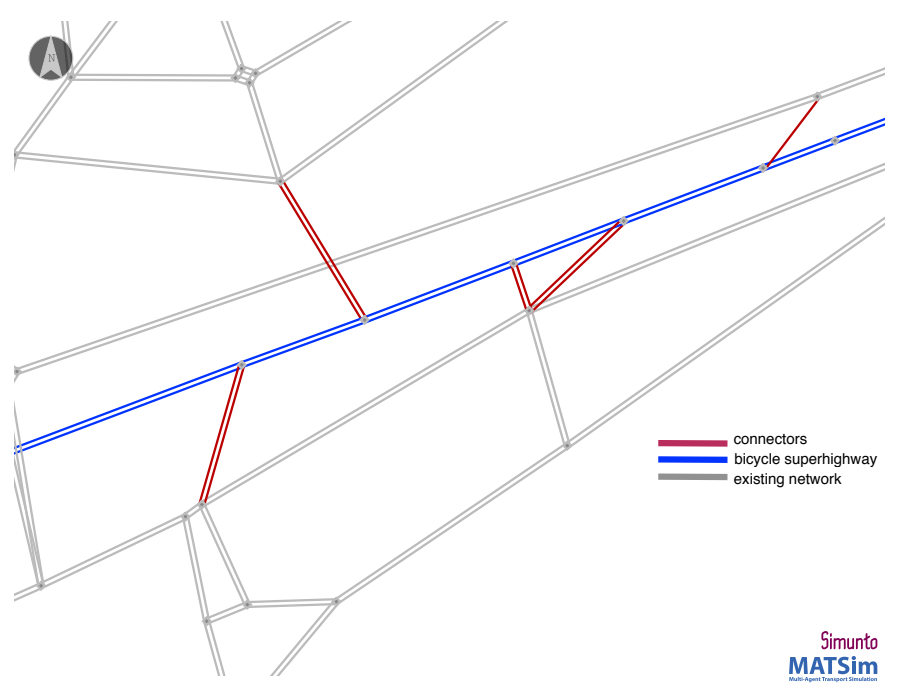

Figure 1: A snippet of the final combined network.

To be an efficient improvement for the transport system and provide a reasonable alternative for travellers, the new infrastructure needs to be easily accessible by travellers. The ease of access depends on the links, which connect the existing network to the new 
Algorithm 1: Identification of connectors between existing network and bicycle superhighway.

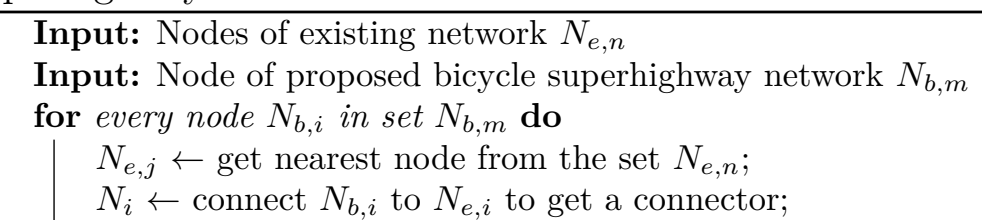

Output: Number of connectors $\left(N_{c}\right)$ between bicycle superhighway and existing network

Output: Combined network

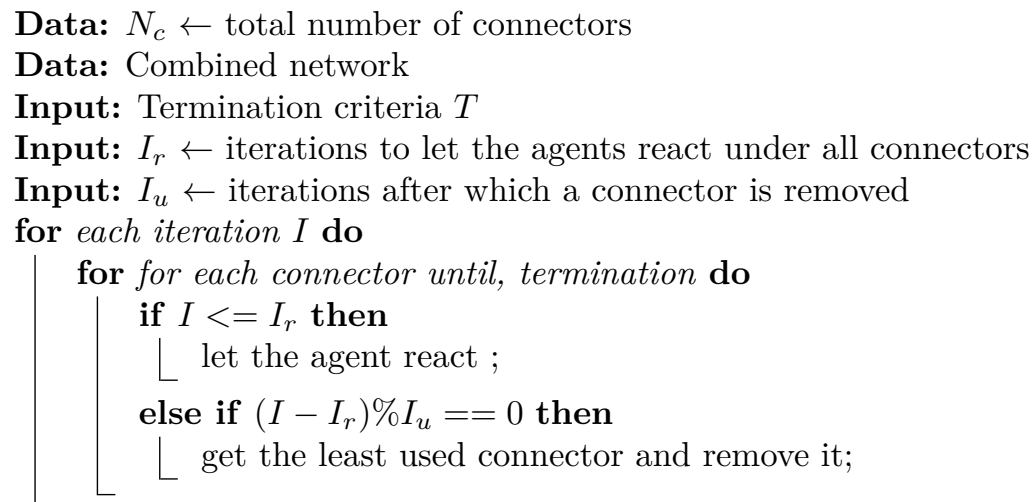

Output: A subset of $N_{c}$ which represents optimum number and locations of connectors between bicycle superhighway and existing network identified using the termination criteria $(T)$.

Output: Final combined network

highway. In this study, these links are referred to as connectors. Two kinds of connectors between the existing network and the bicycle superhighway can be distinguished: (a) connecting links on either side of the railway track (b) connecting links on same side of the railway track. Since, the existing railway track is on ground, in the former case, an ideal connector would be overhead/underpass in form of on/off-ramps whereas, for the latter case, desirable connector would be on ground. On the other hand, if the bicycle superhighway is elevated, all connectors would be on/off ramps.

Too few connectors would impair the usability of the bicycle superhighway whereas too many connectors will increase the construction cost. Therefore, an efficient planning of the connectors is critical. This study proposes an algorithm (Algo. 1) to identify the optimum number and locations of bicycle superhighway connectors. (1) In the first part of the algorithm, all possible connectors between the bicycle superhighway and the existing network are identified. $N_{b, m}$ represents a set of $m$ nodes for bicycle superhighway whereas $N_{e, n}$ represents a set of $n$ nodes for existing network. For every node $\left(N_{b, i}\right)$ in $N_{b, m}$, a nearest node $\left(N_{e, j}\right)$ in the set $N_{e, n}$ is identified. From these nodes, two links in both directions (from $N_{b, i}$ to $N_{e, j}$ and from $N_{e, j}$ to $N_{b, i}$ ) are added to the existing network, these new links are named as 'connectors'. The resulting network is called the combined network. (2) In the next step, for initial $I_{r}$ iterations, agents can change their behaviour with respect to available choice dimensions (e.g. change mode, route, time etc.). A too low value of $I_{r}$ would not be able to exploit the full potential of users' reactions therefore, the value should be high enough so that further increase in $I_{r}$ does not yield any significant increase in the bicycle share. (3) Thereupon, after every $I_{u}$ iterations, the least used connector is identified and removed from the combined network. The parameter $I_{u}$ should be smaller than $I_{r}$ and large enough such that significant changes are not observed in a few previous iterations. In other words, during these iterations, 
agents react in absence of removed connector and switch to other route/mode. (4) The process is continued until the termination criterion is reached. A termination criterion is determined based on the objective of the new highway, e.g. terminate as soon as bicycle share starts dropping, terminate after pre-specified number of connectors $\left(N_{c}\right)$, terminate if the cost of connectors has reached a certain value, etc. Eventually, this algorithm returns a network with an optimum number and location of connectors based on the given objective for the superhighway. Fig. 1 shows part of the existing network, bicycle superhighway and connectors between them. In practice, multiple connectors within a short stretch should be merged. While the proposed algorithm is applied in the context of bicycle superhighway in this study, it is also suitable for any other scenario and for any other travel simulator which allows individual travellers to interact, learn and adapt to the system.

\section{Travel simulator}

In this study, the activity-based, multi-agent transport simulation framework MATSim (Horni et al., 2016) is chosen because of the following properties:(a) The underlying network algorithm is a queue model which controls agents at entry/exit of the link only (Gawron, 1998; Cetin et al., 2003). This makes it computationally fast and suitable for large-scale scenarios. (b) The simulation of a sampled population of agents is possible (Agarwal et al., 2017a). (c) It is embedded into an iterative co-evolutionary algorithm, in which agents interact, learn and adapt to the system and to, e.g. price levels (tolls). This iterative cycle is shown in Fig. 2 and explained in the following.

The essential inputs for a simulation experiment are physical boundary conditions (i.e. network) and daily plans of individual travellers. It is possible to set the scenariospecific parameters (e.g. utility parameters, choice dimensions, travel modes etc.) in the configuration of the simulation experiment. The iterative cycle consists of three parts: Mobsim, scoring and replanning.

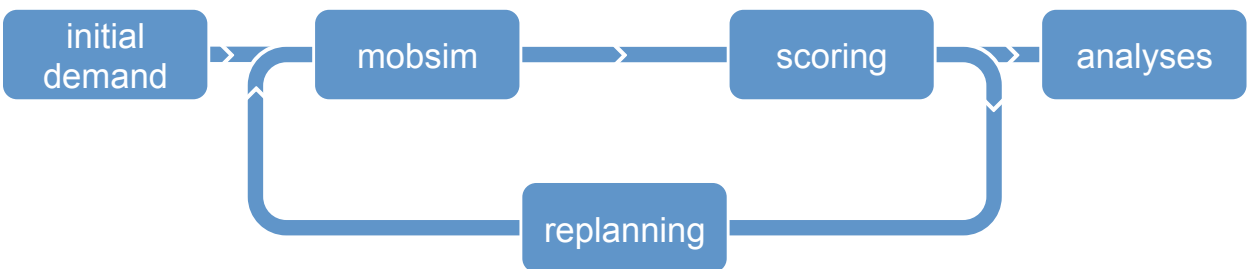

Figure 2: Iterative cycle of MATSim

(1) Mobsim: In this step, the plans of all individual travellers are loaded onto the network simultaneously. Therefore, this step is known as plan execution or mobility simulation (mobsim). For the network loading algorithm, a time-step based queue model is used (Gawron, 1998; Cetin et al., 2003). The traffic dynamics of the queue model resemble Newell's simplified kinematic wave model (Agarwal et al., 2016, 2017a). The underlying queue model can simulate mixed traffic conditions for different link dynamics (Agarwal et al., 2015; Agarwal and Lämmel, 2016). 
(2) Scoring: Simulated plans are evaluated using a utility (or scoring) function. Typically a plan's score $\left(S_{\text {plan }}\right)$ consists of two parts:

$$
S_{\text {plan }}=\sum_{q=0}^{N-1} S_{a c t, q}+\sum_{q=0}^{N-1} S_{\text {trav }, \operatorname{mode}(q)}
$$

where $N$ is number of activities, $S_{a c t, q}$ is the utility for performing activity $q$ and $S_{\text {trav, } \operatorname{mode}(q)}$ is the utility of travelling (typically negative) from activity $q$ to activity $q+1$ by mode mode. The former part aggregates the utilities for an agent while performing different activities (see Nagel et al., 2016, for a more detailed explanation). The latter part is the sum of the utilities gained for travelling between different activities (see Sec. 4.2.2 and Eq. (1)). To produce an equal number of activities and trips, the first and the last activity are scored together and, therefore, the aggregation is up to $N-1$.

(3) Replanning: In this step, agents react and adapt to the system depending on the available choice dimensions (e.g. route choice, mode choice, time choice etc.). Replanning consists of two parts: Plan innovation and plan selection. In the former, a new plan is created and then executed in the next iteration. The new plan is generated by modifying an existing plan according to given choice dimensions. In the plan selection step, agents select a plan from the generated choice set according to a probability distribution which converges to a multinomial logit model (Nagel and Flötteröd, 2012).

\section{Application of a bicycle superhighway to Patna, India}

For the application of bicycle superhighway, a real-world case study of Patna, India is chosen. Situated along River 'Ganga', Patna is one of the most populous cities in the eastern part of India. The population of the Patna agglomeration area was 5.77 million in 2011 (Census, 2011). The study area includes 72 zones of the Patna Municipal Corporation (PMC). The scenario used in this study was developed by Agarwal et al. (2017b) and briefly explained in the following.

\subsection{Scenario setup}

The digital network of Patna is created using TransCAD (TransCAD, 2012) files. The three major arterials are 'Ashok Rajpath', the 'old bypass' and the 'new bypass', which all extend in east-west direction. The travel demand of the region is categorized into the two groups of 'urban travel demand' and 'external travel demand'.

The urban travel demand is synthesized directly from a trip diary survey (TRIPP et al., 2009, Patna Comprehensive Mobility Plan, (Patna, CMP)). A total of 13,278 plans are recorded, which constitutes approximately a $1 \%$ sample of the full population of Patna. In order to obtain a $10 \%$ sample, each record is cloned by randomizing the origins, destinations and departure times of the trips. Travel modes for urban trips are bicycle, car, motorbike, public transport (PT) and walk. The modal share for these modes is $33 \%$, $2 \%, 14 \%, 22 \%$ and $29 \%$, respectively (TRIPP et al., 2009).

The external travel demand is further classified as through traffic and commuter traffic. Through traffic simply passes through Patna. Commuters are individuals who commute between Patna and nearby areas. These travellers make at most two trips a day. Travel modes for external demand are bicycle, car, motorbike and truck. Patna CMP provides 
classified hourly counts for 7 outer cordon stations in both directions. This alone is insufficient to generate daily plans. Thus, daily plans for external demand are created by extending CaDyTS (Flötteröd, 2009) for mixed traffic (see Agarwal et al., 2017b; Agarwal, 2017, for more details about the calibration process).

\subsection{Simulation preparation}

\subsubsection{Travel modes}

For the simulation, the combined travel demand (urban and external) is used. The bicycle, car, motorbike and truck modes are physically simulated on the network (and called 'main modes' or 'congested modes' in MATSim), whereas the PT and walk modes are teleported between origin and destination. The flow and storage capacities of a link are observed for congested mode (see Agarwal, 2017, for more details). The maximum free speeds and passenger car equivalents $(\mathrm{PCE})^{5}$ for different congested modes and teleportation speed for teleported modes are shown in Tab. 2.

Table 2: Modal attributes for Patna scenario.

\begin{tabular}{l|rrrr|rr}
\hline & \multicolumn{5}{|c|}{ Maximum free speed } & Teleportation speed \\
\cline { 2 - 7 } & Bicycle & Car & Motorbike & Truck & PT & Walk \\
\hline Speed $(k m / h)$ & 15 & 60 & 60 & 30 & 20 & 5 \\
PCE & 0.15 & 1 & 0.15 & 3 & - & - \\
\hline
\end{tabular}

\subsubsection{Utility function}

Variations in household incomes are likely to affect travel behaviour of individual travellers. Therefore, the effect of household income is included in the scoring function (Agarwal et al., 2017b). The mode-specific utility function for trip $q$ given as follows: ${ }^{6}$

$$
\begin{aligned}
S_{\text {trav }, \text { bicycle }, q} & =C_{\text {bicycle }}+\beta_{\text {trav }, \text { bicycle }} \cdot t_{\text {trav }, q}+\beta_{\text {d,bicycle }} \cdot d_{\text {trav }, q} \\
S_{\text {trav }, \text { car }, q} & =C_{\text {car }}+\beta_{\text {trav }, \text { car }} \cdot t_{\text {trav }, q}+\frac{\bar{y}}{y_{j}} \cdot \frac{1}{\mathrm{USD}} \cdot\left(\gamma_{d, c a r} \cdot d_{\text {trav }, q}\right) \\
S_{\text {trav }, m b, q} & =C_{m b}+\beta_{\text {trav }, m b} \cdot t_{\text {trav }, q}+\frac{\bar{y}}{y_{j}} \cdot \frac{1}{\mathrm{USD}} \cdot\left(\gamma_{d, m b} \cdot d_{\text {trav }, q}\right) \\
S_{\text {trav }, P T, q} & =C_{P T}+\beta_{\text {trav }, P T} \cdot t_{\text {trav }, q}+\frac{\bar{y}}{y_{j}} \cdot \frac{1}{\mathrm{USD}} \cdot\left(\gamma_{d, P T}\left(d_{\text {trav }, q}\right)\right) \\
S_{\text {trav }, \text { walk }, q} & =C_{\text {walk }}+\beta_{\text {trav }, \text { walk }} \cdot t_{\text {trav }, q}+\beta_{d, \text { walk }} \cdot d_{\text {trav }, q}
\end{aligned}
$$

$C_{\text {mode }}$ is the alternative-specific constant for mode mode, $t_{\text {trav }}$ is the travel time (in $h$ ) between two activities, $d_{\text {trav }}$ is the travelled distance (in $\mathrm{km}$ ) between two activities, $\beta_{d, \text { mode }}$ is the marginal utility of distance (in util $/ \mathrm{km}$ ) for mode mode (normally negative or zero),

\footnotetext{
${ }^{5}$ Please note that PCE is used only to note down the consumption of flow and storage capacity of a link in the queue model (Agarwal et al., 2017a, 2015). It is not used to convert heterogeneous traffic flow into a homogeneous traffic flow. Each vehicle is considered individually with its own attributes.

${ }^{6}$ For truck, a different behavioural model is required which is out of scope for the present study. However, the congestion effect of the commercial vehicles is included in the simulation and default utility parameters are used for them (cf. Agarwal, 2017, Ch. 9, for further details about the commercial traffic in the model).
} 
Table 3: Utility parameters (Agarwal et al., 2017b)

\begin{tabular}{|c|c|c|c|c|c|}
\hline Travel mode & Bicycle & Car & Motorbike & $\mathbf{P T}$ & Walk \\
\hline $\begin{array}{l}\text { Alternative-specific constant } \\
(C) \text { [util] }\end{array}$ & 0.0 & -0.6 & -0.58 & -0.545 & 0.0 \\
\hline $\begin{array}{l}\text { Marginal utility of travelling } \\
\left(\beta_{\text {trav }}\right)[\mathrm{util} / h]\end{array}$ & -0.12 & -0.0 & -0.12 & -0.40 & -0.12 \\
\hline $\begin{array}{l}\text { Monetary distance rate } \\
\left(\gamma_{d}\right)[\mathrm{USD} / \mathrm{km}]\end{array}$ & - & -0.037 & -0.016 & - Eq. (2) & - \\
\hline $\begin{array}{l}\text { Marginal utility of distance } \\
\left(\beta_{d}\right)[\mathrm{util} / \mathrm{km}]\end{array}$ & -0.11 & - & - & - & -0.12 \\
\hline \multicolumn{3}{|c|}{ Marginal utility of performing $\left(\beta_{d u r}\right)[u t i l / h]$} & \multicolumn{2}{|c|}{0.19} & \\
\hline
\end{tabular}

$\beta_{\text {trav,mode }}$ is the marginal utility of travelling (in util $/ h$ ) for mode mode (normally negative or zero), $\gamma_{d \text {,mode }}$ is the monetary distance rate (in USD $/ \mathrm{km}$ ) for mode mode (normally negative or zero), $\bar{y}$ is the median income of all individuals and $y_{j}$ is the household income of individual $j$. The utility parameters are shown in Tab. 3. For PT, a distance-based cost is used:

$$
\gamma_{d, p t}(d)=\mathrm{PT} \text { trip costs }[\mathrm{USD}]= \begin{cases}0.045, & \text { if } d[\mathrm{~km}] \leq 4 \mathrm{~km} \\ 0.045+(d-4) \cdot 0.0047, & \text { if } d[\mathrm{~km}]>4 \mathrm{~km}\end{cases}
$$

where $d$ is given in $k m .^{7}$

In addition, there is a positive utility for performing an activity:

$$
S_{a c t, q}=\beta_{d u r} \cdot t_{t y p, q} \cdot \ln \left(t_{d u r, q} / t_{0, q}\right)
$$

where $t_{d u r, q}$ and $t_{t y p, q}$ are actual and typical durations of activity $q$, respectively. $\beta_{d u r}$ is the marginal utility of activity duration (or marginal utility of performing) and $t_{0, q}$ is the activity duration at which utility starts to be positive. ${ }^{8}$

All scores are added up over the day:

$$
S=\sum_{q=0}^{N-1} S_{a c t, q}+\sum_{q=0}^{N-1} S_{t r a v, \operatorname{mode}(q)} .
$$

Note that there are as many trips as there are activities since it is assumed that the last activity of the day is "wrapped around" and merged with the first one.

The interpretation of the utility parameters and value of travel time saving is explained next. In the model, having a longer trip has two consequences:

\footnotetext{
${ }^{7}$ This corresponds to 3 INR up to a distance of $4 \mathrm{~km}$, and an additional 0.31 INR per additional $\mathrm{km}$. These fares were charged in Patna around 2004 (Kumar et al., 2004).

${ }^{8} t_{0, q}$ is given by

$$
t_{t y p, q} \cdot \exp \left(\frac{-10}{\left.\frac{t_{t y p, q} \cdot p}{1 h}\right)}\right.
$$

This is designed in a way that all activities at their typical durations $\left(t_{t y p, q}\right)$ will have same utility of performing i.e.

$$
\left.S_{a c t, q}\right|_{t_{d u r, q}=t_{t y p, q}}=\beta_{d u r} \cdot 10 h
$$
}


(a) There is direct dis-utility of travelling coming from Eq. (1).

(b) In addition, there remains less time for performing activities. This is often called the effect of the marginal utility of time as a resource, or the opportunity cost of time. That is, an increase in the travel time by $\Delta t$ using mode mode, an agent loses $-\beta_{\text {trav,mode }} \times$ $\Delta t$ for travelling (note that $\beta_{\text {trav,mode }}$ is negative, see Tab. 3). Additionally, it loses $\beta_{d u r} \times \frac{t_{t y p}}{t_{d u r}, q} \times \Delta t$ for not performing an activity. Following this, the value of travel time savings of an activity is given by dividing the sum of these two terms by the marginal utility of money, which according to Eq. (1) is $\bar{y} / y_{j}$, i.e.

$$
V T T S_{j}=\frac{-\beta_{\text {trav }, \text { mode }}+\beta_{\text {dur }} \frac{t_{\text {typ }, q}}{t_{d u r, q}}}{\frac{\bar{y}}{y_{j}} \cdot \frac{1}{\mathrm{USD}}},
$$

or, at the typical duration $t_{d u r, q}=t_{t y p, q}$ :

$$
\operatorname{VTTS}_{j}=\frac{-\beta_{\text {trav }, \text { mode }}+\beta_{\text {dur }}}{\frac{\bar{y}}{y_{j}} \cdot \frac{1}{\mathrm{USD}}} .
$$

Evidently, this depends on the income $y_{j}$ of agent $j$ (Agarwal et al., 2017b, for further details). Thus, the mode-specific value of travel times savings, when activities are performed at their typical durations, are:

$$
\begin{aligned}
& \text { VTTS }_{\text {car }}=\frac{-(-0.0)+0.19}{\bar{y} / y_{j}} \quad \frac{\mathrm{USD}}{h}=0.19 \times \frac{y_{j}}{\bar{y}} \quad \frac{\mathrm{USD}}{h} \\
& \text { VTTS }_{\text {motorbike }}=\frac{-(-0.12)+0.19}{\bar{y} / y_{j}} \quad \frac{\mathrm{USD}}{h}=0.31 \times \frac{y_{j}}{\bar{y}} \quad \frac{\mathrm{USD}}{h} \\
& \operatorname{VTTS}_{P T}=\frac{-(-0.40)+0.19}{\bar{y} / y_{j}} \quad \frac{\mathrm{USD}}{h}=0.59 \times \frac{y_{j}}{\bar{y}} \quad \frac{\mathrm{USD}}{h}
\end{aligned}
$$

This means that the willingness-to-pay to reduce the travel time is explained by a combination of the general inconvenience of the mode and the income of the traveller. These VTTS may seem rather low, but IRC:SP:30 (2009) recommends VTTS in the same range, and the conversion from those values to our income-dependent values is discussed by Agarwal et al. (2017b).

\subsubsection{Policy scenarios under consideration}

It is proposed to construct the bicycle superhighway along the railway line because

1. it is more likely that there is enough space available on both side of the railway line,

2. the railway runs from the east to the west of the city and

3. it is parallel to the one of the major arterials (see Fig. 3).

Since it is a physically segregated bicycle superhighway (rather than a bicycle lane parallel to arterials), motorbikes can be restricted by law enforcement. Both possibilities, a case where the bicycle superhighway may only be used by cyclists and a case where also motorbikes are allowed on the bicycle superhighway, are compared in this study. A scenario for Patna, which is used for theses analysis, was created and calibrated by Agarwal et al. (2017b). It is referred to as the base case in this study. The output of the base case is used as input for all scenarios under consideration. The first scenario is business as usual which is used to compare the output of two policies. Overall, the following three scenarios are considered for Patna. 


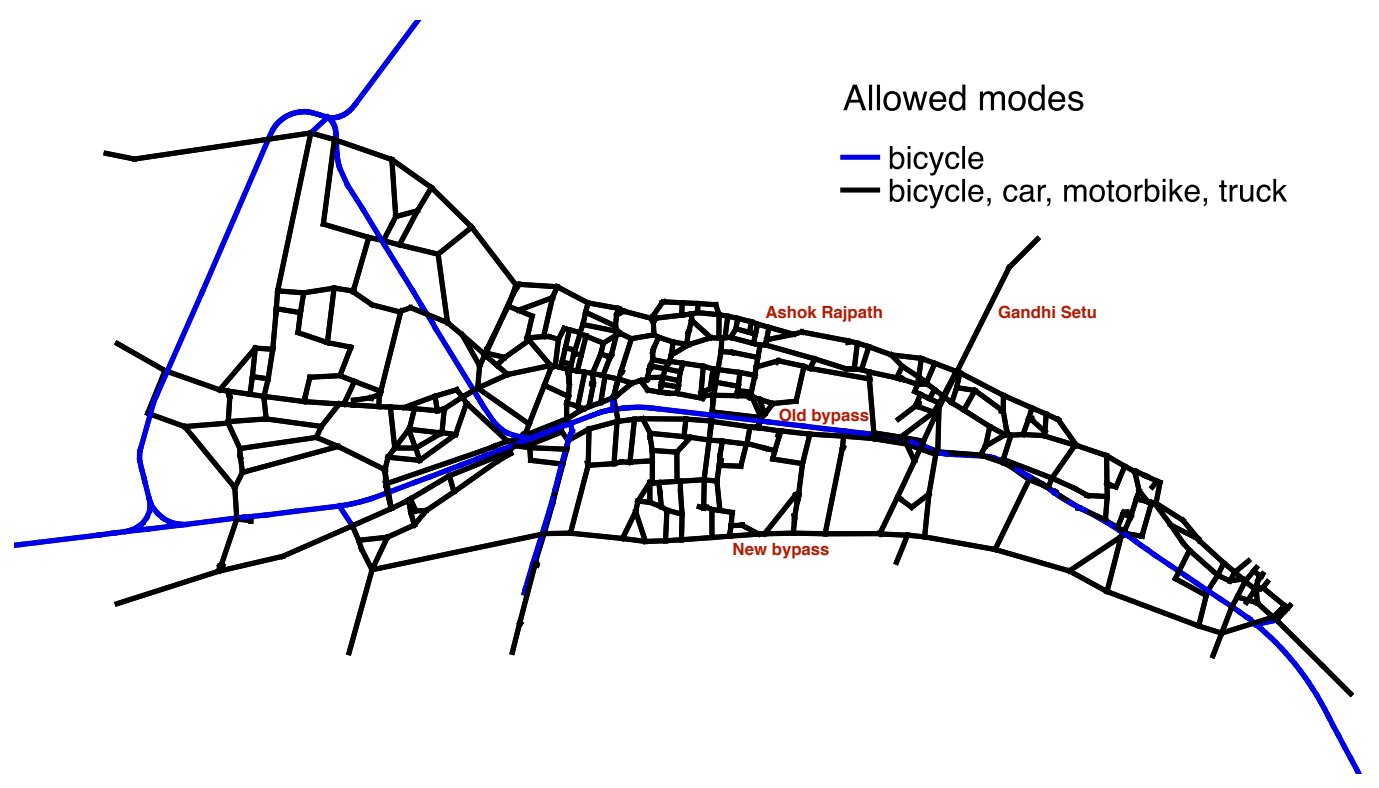

Figure 3: Patna network with bicycle superhighway.

\footnotetext{
${ }^{9}$ Technically, this is achieved by giving each link of the bicycle superhighway only half of its true length.
}

1. BAU: Business as usual

2. BSH-b: Bicycle superhighway used by bicycle mode only

3. BSH-mb: Bicycle superhighway used by motorbike and bicycle modes.

\subsubsection{Policy setup}

Connectors to bicycle superhighway A bicycle superhighway is created parallel to the railway track within Patna as shown in Fig. 3. The optimum number and locations of entries/exits to/from the bicycle superhighway is determined based on an optimization approach (see Algo. 1). For each link of the bicycle superhighway, it is assumed that bicycles are about two times faster than on the regular network and that the effort to ride a bicycle is reduced to its half. ${ }^{9}$ As described in Sec. 2 , the objective of the identification of the connectors could be constrained by the cost of construction or on other factors. However, in this study, the objective is to find the minimum number of connectors, which allows for a maximum share of bicycle trips. The algorithm filters out the less desirable locations of the connectors.

In Algo. 1, the agents are initially allowed to make decisions in the presence of all connectors for 100 iterations $\left(=I_{r}\right)$. Mode choice is allowed for urban travellers until the termination of the simulation run. Therefore, in the first step, agents react to the new bicycle superhighway and switch to bicycle mode. Afterwards, the link used the least (by cyclists) is removed after every 10 iterations $\left(=I_{u}\right)$ until termination.

The variation in modal share over iterations is shown in Fig. 4. From this, it can be observed that, initially, in presence of all possible connectors, the bicycle share (depicted in orange colour) increases steeply, reaches its maximum value and remains constant until 4500 iterations. After 4500 iterations, the share of bicycle starts decreasing. Therefore, the connectors at iteration 4500 are taken as the optimum number of connectors. The resulting network is chosen for the two policy measures (BSH-b and BSH-mb). 


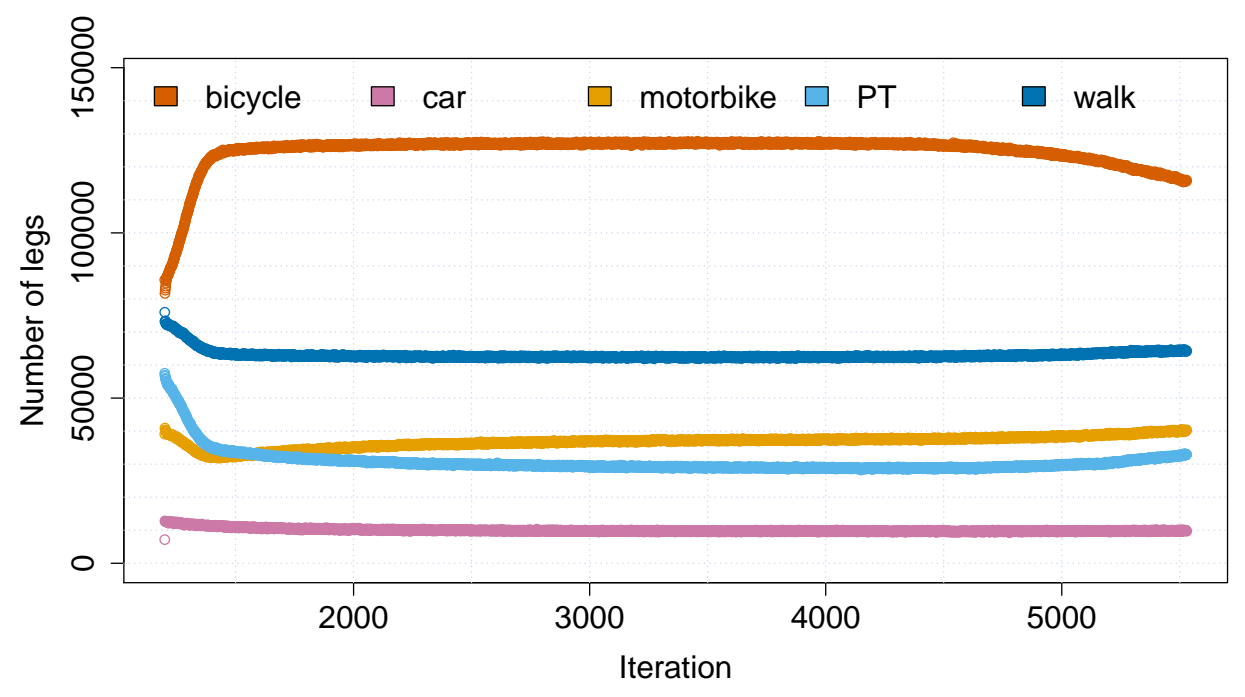

Figure 4: Modal share of urban travellers during identification of bicycle superhighway connectors.

Replanning strategies of policy scenarios All three scenarios (see Sec. 4.2.3) are run for 200 iterations. For the BAU scenario, the existing network is used, whereas for the other two scenarios, the network with the bicycle superhighway and its connectors is used. For re-planning, 'plan innovation' is used until $80 \%$ of the iterations. During this, in each iteration, $10 \%$ of urban travellers are allowed to change their mode and $15 \%$ are allowed to change their route. For all external trips, $15 \%$ of agents are allowed to change their routes only. The rest of the agents (i.e. $75 \%$ of urban travellers and $85 \%$ of externaldemand agents) select a plan from their generated choice sets. ${ }^{10}$ After plan innovation is switched of, all agents may only select from their choice sets until the end of the simulation run.

\section{Results}

This section presents and compares the results of the three scenarios. Firstly, in order to show the impact of the bicycle superhighway, the congestion patterns of the three scenarios are presented in Sec. 5.1. This is followed by a comparison of the modal split for all three scenarios in Sec. 5.2 and an detailed analysis of the mode switchers and retainers in Sec. 5.3. The effect of the bicycle superhighway on emissions and accessibility is spatially visualised in Secs. 5.4 and 5.5, respectively. The results of the two policy scenarios (BSH-b and BSH-mb) are compared with the BAU scenario. The results are based on the analysis of urban travellers only, while external demand has been added to complete the model in terms of congestion patterns.

\subsection{Congestion patterns}

Fig. 5 shows a comparison of the congestion patterns ${ }^{11}$ of three scenarios for car, motorbike and bicycle traffic at 08:00:00. The left column (Figs. 5a, 5d and 5g) shows the

\footnotetext{
${ }^{10}$ Refer to Kickhöfer et al. (Fig. 3, 2018) for an example, which shows plan innovation and plan selection for the business as usual scenario as well as for a policy scenario.

11 These congestion patters are generated using the visualization tool VIA (see http://www.via.simunto. com).
} 


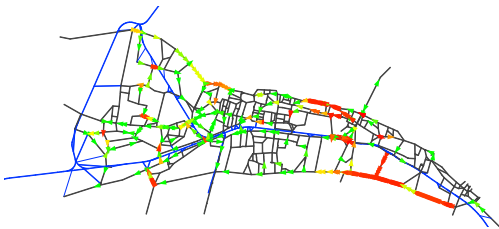

(a) Car, BAU scenario

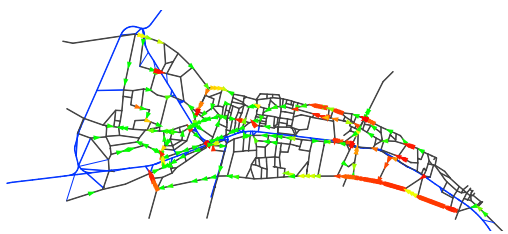

(d) Car, BSH-b scenario

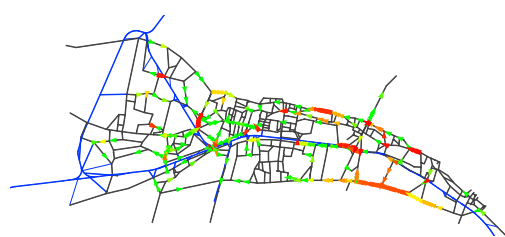

(g) Car, BSH-mb scenario

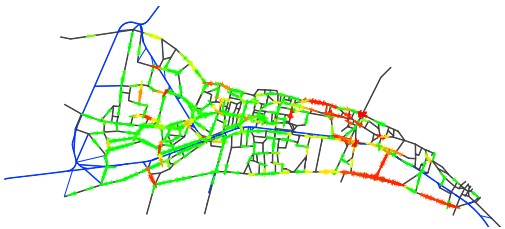

(b) Motorbike, BAU scenario

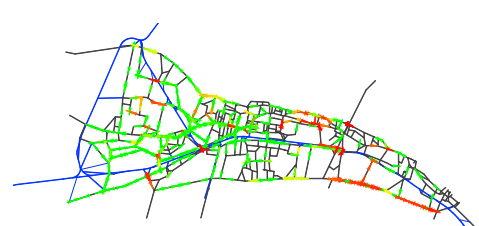

(e) Motorbike, BSH-b scenario

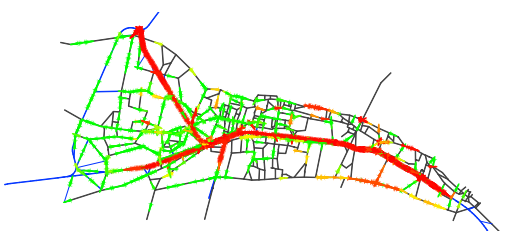

(h) Motorbike, BSH-mb scenario

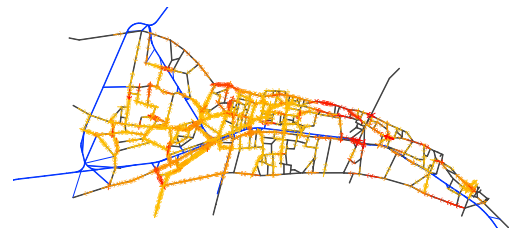

(c) Bicycle, BAU scenario

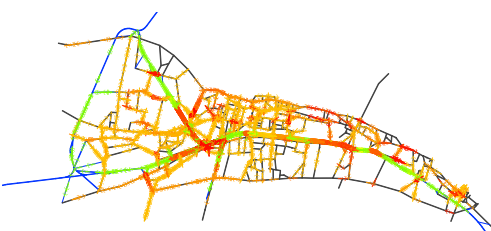

(f) Bicycle, BSH-b scenario

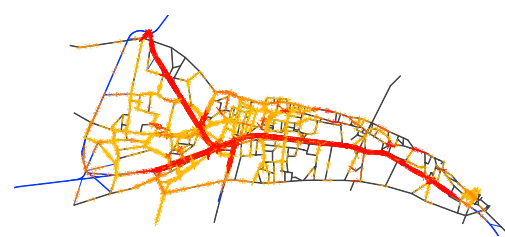

(i) Bicycle, BSH-mb scenario

Figure 5: Comparison of the congestion patterns at 08:00:00 for three scenarios.

congestion patterns for car. A capacity relief on the new bypass and 'Ashok Rajpath' can be observed in the BSH-b and BSH-mb scenarios. The traffic patterns on the remaining roads for car traffic remain largely the same in the three scenarios because the share of the car does not change much (approximately 2\%; Tab. 4). The middle column (Figs. 5b, $5 \mathrm{e}$ and $5 \mathrm{~h}$ ) shows the congestion patterns for the motorbike mode. In the former two, the queues on several streets near Gandhi Setu and other parts of Patna have been reduced or fully dissolved, whereas long queues appear in the latter (BSH-mb) scenario, which is an effect of allowing motorbikes on the bicycle superhighway. The right column (Figs. 5c, $5 \mathrm{f}$ and $5 \mathrm{i}$ ) shows the congestion patterns for bicycle traffic. In the BSH-b scenario, a few small bicycle queues appear on a few links of the bicycle superhighway, while the length of the queues on the other streets of the network has decreased. The queues become longer in the BSH-mb scenario, in which both motorbikes and bicycles travel on the bicycle superhighway. Overall, a capacity relief on the southern arterial (going east to west; new bypass) and other streets can be observed (also see Sec. 5.3.2).

\subsection{Modal split}

Table 4: Modal splits for urban travellers (in \%) for various policy scenarios.

\begin{tabular}{lccrrr}
\hline Mode & Reference study & Base case & BAU & BSH-b & BSH-mb \\
\hline Bicycle & 33.0 & 32.3 & 32.5 & 48.7 & 44.0 \\
Car & 2.0 & 2.7 & 2.5 & 2.1 & 1.9 \\
Motorbike & 14.0 & 14.7 & 15.3 & 11.2 & 18.5 \\
PT & 22.0 & 21.7 & 21.2 & 12.9 & 10.3 \\
Walk & 29.0 & 28.6 & 28.6 & 25.1 & 25.3 \\
\hline
\end{tabular}


Tab. 4 shows the modal splits for various scenarios. In the business-as-usual scenario (BAU), the modal split is about the same as the base case scenario and the reference study. The effect of the bicycle superhighway is clearly visible in the BSH-b and BSH-mb scenarios. In the BSH-b scenario, approximately half of the urban trips are made by the bicycle mode. The increase in the bicycle share comes mainly from the PT mode and partly from the motorbike and the walk mode (also see Tab. 5b). This is plausible since a significant number of households belongs to the low income group. On the other hand, in the BSH-mb scenario, the superhighway is an attractive option for motorbike riders as well, which increases the share of the motorbike mode to more than $18 \%$ and reduces the share of the bicycle mode to $44 \%$. This is significantly higher than the modal share in BAU scenario, but, at the same time, less than the modal share in the BSH-b scenario. A more detailed analysis for mode switchers and retainers is given in the next section.

\subsection{Mode switcher analysis}

\subsubsection{Change in the numbers of trips}

Tab. 5a shows the number of trips of mode switchers (e.g. car to bicycle, motorbike to car, etc.) and mode retainers (the diagonal values in the matrix; e.g. car to car, bicycle to bicycle, etc.) for the BAU scenario. Clearly, as expected, for the BAU scenario, most of the agents retain their modes.

Tab. 5b and Tab. 5c show the change in the numbers of trips of mode switchers/retainers in the BSH-b and BSH-mb policy scenarios, respectively, with respect to the BAU scenario. In the BSH-b scenario, with respect to BAU, the increase in the bicycle share mainly comes from motorbike, PT and walk to bicycle mode switchers (11712, 20330 and 9058 trips, respectively). The contributions of motorbike, PT and walk to bicycle mode switchers have significantly decreased in the BSH-mb scenario (7166, 13560 and 8594 trips, respectively). This is an effect of allowing motorbikes on the bicycle superhighway. In addition to this, for BSH-mb scenario,

- a significant number of PT trips is shifted to the motorbike mode (12892 trips) and

- the number of motorbike retainers is approximately 5000 higher than the number of motorbike retainers in the BSH-b scenario.

The driving forces behind this are discussed in the next section.

\subsubsection{Change in the average speed}

Tab. 6 shows the changes in average route speed and in average beeline speed for mode switcher/retainer. The changes are computed with respect to the first iteration (it.1200) of each policy measure, which is same for all scenarios. The route speed is the ratio of the route distance (along travelled links) ${ }^{12}$ to the travel time in the simulation whereas the beeline speed is the ratio of the direct distance between the activity locations (beeline distance) to the travel time. ${ }^{13}$

\footnotetext{
${ }^{12} \mathrm{As}$ mentioned before in Sec. 4.2.4, to make bicycles twice as fast on the bicycle superhighway as on the normal network, the lengths of the links of bicycle superhighway have been halved. For the analysis of the average route speeds, the actual link lengths of the bicycle superhighway are taken, while increasing the speeds of the bicycle to the double on these links.

${ }^{13}$ In general, if the activity locations do not change, a positive change in average beeline speed translates into a lower travel time for the same beeline distance and vice versa.
} 
Table 5: Analysis of the numbers of trips of mode switcher/retainer.

(a) Absolute number of trips in the BAU scenario

\begin{tabular}{|c|c|c|c|c|c|c|c|}
\hline & & \multicolumn{5}{|c|}{ Last iteration (it.1400) } & \multirow[b]{2}{*}{ Total } \\
\hline & & Bicycle & Car & Motorbike & $\mathbf{P T}$ & Walk & \\
\hline \multirow{5}{*}{$\begin{array}{l}\text { First } \\
\text { iteration } \\
\text { (it.1200) }\end{array}$} & Bicycle & 82408 & 56 & 430 & 774 & 2140 & 85808 \\
\hline & Car & 48 & 4772 & 1712 & 622 & 2 & 7156 \\
\hline & Motorbike & 526 & 1056 & 36186 & 1308 & 16 & 39092 \\
\hline & $\mathbf{P T}$ & 1084 & 702 & 2296 & 53408 & 28 & 57518 \\
\hline & Walk & 2176 & 4 & 18 & 22 & 73766 & 75986 \\
\hline
\end{tabular}

(b) Changes in the numbers of trips in the BSH-b scenario with respect to the BAU scenario

\begin{tabular}{ll|rrrrr}
\hline & & \multicolumn{4}{|c}{ last iteration (it.1400) } \\
\cline { 3 - 7 } & & Bicycle & Car & Motorbike & PT & Walk \\
\hline \multirow{2}{*}{ First } & Car & +1092 & -28 & -228 & -484 & -352 \\
iteration & Motorbike & +11712 & -348 & -10674 & -682 & -8 \\
(it.1200) & PT & +20330 & +210 & +74 & -20618 & +4 \\
& Walk & +9058 & -2 & -10 & 0 & -9046 \\
\hline
\end{tabular}

(c) Changes in the numbers of trips in the BSH-mb scenario with respect to the BAU scenario

\begin{tabular}{ll|rrrrr}
\hline & & \multicolumn{4}{c}{ Last iteration (it.1400) } \\
\cline { 3 - 7 } & Bicycle & +942 & -26 & -204 & -522 & -190 \\
& Bicycle & Car & Motorbike & PT & Walk \\
\hline \multirow{2}{*}{ First } & Car & +542 & -1734 & +1538 & -344 & -2 \\
iteration & Motorbike & +7166 & -432 & -5806 & -920 & -8 \\
(it.1200) & PT & +13560 & +554 & +12892 & -27014 & +8 \\
& Walk & +8594 & -4 & +64 & -2 & -8652 \\
\hline
\end{tabular}

Tab. 6a and Tab. 6b show the changes in average route speeds and average beeline speeds in the BSH-b scenario, while Tab. 6c and Tab. 6d show the changes in the average route speeds and average beeline speeds in the BSH-mb scenario. In the BSH-b scenario, for bicycle retainers, the average route speed increases by $+1.09 \mathrm{~km} / \mathrm{h}$ and the average beeline speed increases by $+0.37 \mathrm{~km} / \mathrm{h}$. This indicates that bicycles are faster and also travel longer distances. Since a significant number of cyclists use the bicycle superhighway, a capacity relief on the network also increases the average route speeds of car and motorbike retainers $(+3.20$ and $+4.28 \mathrm{~km} / \mathrm{h})$. This also translates in higher beeline speeds $(+2.49$ and $+3.03 \mathrm{~km} / \mathrm{h})$, i.e. reduced origin-to-destination travel times.

The average route speeds for car and motorbike to bicycle mode switchers decrease by -7.28 and $-12.73 \mathrm{~km} / \mathrm{h}$, respectively, whereas the average beeline speeds decrease by -4.88 and $-9.31 \mathrm{~km} / \mathrm{h}$, respectively. This indicates that switching from the car/motorbike 
Table 6: Changes in average speeds for mode switchers/retainers with respect to the first iteration (it.1200).

(a) Changes in average route speeds in the BSH-b scenario

\begin{tabular}{ll|rrrrr}
\hline & & \multicolumn{5}{|c}{ Last iteration (it.1400) } \\
\cline { 3 - 7 } & & Bicycle & Car & Motorbike & PT & Walk \\
\hline \multirow{2}{*}{ First } & Carycle & +1.09 & +13.92 & +17.07 & +9.66 & -5.42 \\
iteration & Motorbike & -12.73 & +2.90 & +4.28 & +3.56 & -26.59 \\
$($ it.1200) & PT & -9.22 & -1.91 & +3.01 & 0.00 & -15.01 \\
& Walk & +6.82 & +30.04 & +19.75 & +15.02 & 0.0 \\
\hline
\end{tabular}

(b) Changes in average beeline speeds in the BSH-b scenario

\begin{tabular}{|c|c|c|c|c|c|c|}
\hline & & \multicolumn{5}{|c|}{ Last iteration (it.1400) } \\
\hline & & Bicycle & Car & Motorbike & $\mathbf{P T}$ & Walk \\
\hline \multirow{5}{*}{$\begin{array}{l}\text { First } \\
\text { iteration } \\
(\text { it.1200) }\end{array}$} & Bicycle & +0.37 & +9.47 & +11.47 & +5.50 & -3.22 \\
\hline & Car & -4.88 & +2.49 & +4.82 & +2.94 & - \\
\hline & Motorbike & -9.31 & +2.33 & +3.03 & +1.24 & -15.20 \\
\hline & $\mathbf{P T}$ & -5.39 & +0.29 & +2.49 & 0.00 & -10.16 \\
\hline & Walk & +2.90 & +16.09 & +10.74 & +9.78 & 0.0 \\
\hline
\end{tabular}

(c) Changes in average route speeds in the BSH-mb scenario

\begin{tabular}{ll|rrrrr}
\hline & & \multicolumn{5}{c}{ Last iteration (it.1400) } \\
\cline { 3 - 7 } & & Bicycle & Car & Motorbike & PT & Walk \\
\hline \multirow{2}{*}{ First } & Bicycle & -2.34 & +7.26 & +14.07 & 9.74 & -5.83 \\
iteration & Motorbike & -21.87 & +2.70 & -3.95 & +1.51 & -25.21 \\
(it.1200) & PT & -13.24 & -1.67 & -8.40 & 0.00 & -15.01 \\
& Walk & +2.90 & - & +14.56 & +15.01 & 0.0 \\
\hline
\end{tabular}

(d) Changes in average beeline speeds in the BSH-mb scenario

\begin{tabular}{ll|rrrrr}
\hline & & \multicolumn{5}{c}{ Last iteration (it.1400) } \\
\cline { 3 - 7 } & & Bicycle & Car & Motorbike & PT & Walk \\
\hline \multirow{2}{*}{ First } & Bicycle & -1.76 & +4.35 & +8.72 & +5.49 & -3.42 \\
iteration & Motorbike & -15.21 & +2.22 & -3.76 & -0.50 & -14.73 \\
(it.1200) & PT & -8.48 & +0.79 & -5.16 & 0.00 & -9.43 \\
& Walk & +0.90 & - & +6.12 & +10.51 & 0.0 \\
\hline
\end{tabular}


to the bicycle makes travel speed considerably slower, while the direct origin-to-destination speed and thus travel times do not suffer as much.

In the BSH-mb scenario, due to congestion on the bicycle superhighway, the average route and beeline speeds for bicycle retainers decreases by $-2.34 \mathrm{~km} / \mathrm{h}$ and $-1.76 \mathrm{~km} / \mathrm{h}$, respectively, i.e. the bicycle retainers move more slowly, which is, however, somewhat compensated by more direct routes. Similar to the BSH-b scenario, the average route speed decreases for car/motorbike to bicycle mode switchers. In contrast to the BSH-b scenario, the average route speeds for car to motorbike switchers and motorbike retainers decrease significantly. Still, they are better off by travelling shorter distances.

From this mode switcher/retainer analysis, it can be summarized that the share of bicycle increases significantly. However, this gain is reduced in case motorbike riders are allowed on the bicycle superhighway as well. Further, a capacity relief effect is also observed. In the next section, the emission externalities for all scenarios are estimated, which will emphasize the important contribution of the bicycle superhighway towards a more sustainable transport system.

\subsection{Emissions calculation \\ 5.4.1. Estimation approach}

In order to assess the impact of the policy scenarios, the emissions are estimated as a post-processing step. An emission modelling tool (EMT) for homogeneous traffic was developed by Hülsmann et al. (2011) and, further improved, extended and integrated to a simulation framework (MATSim, Sec. 3) by Kickhöfer et al. (2013). Total emissions are comprises of cold and warm emissions. The former depends on parking duration, distance travelled and vehicle characteristics; the latter depends on engine type, road type, speed of the vehicles etc. Currently, emissions are estimated for free-flow and stopand-go traffic states. Static vehicle characteristics (e.g. vehicle type, age, cubic capacity, fuel type etc.) are initial input to emission modelling tool. The emissions are estimated as soon as an agent leaves a link. Thus, dynamic attributes (e.g. last engine start time, travelled distance, traffic state etc.) are estimated from the simulation. Thereupon, the HBEFA ${ }^{14}$ database provides cold and warm emissions for given static and dynamic attributes. These agent- and link-specific emissions are then aggregated for different time bins. Further, in order to estimate time-dependent, vehicle- and link-specific emissions from motorbikes and other vehicle types, the EMT is extended to heterogeneous traffic conditions. This approach is used to estimate the emissions ${ }^{14}$ for all three scenarios in the present study.

\subsubsection{Absolute emissions for $B A U$}

Fig. 6 shows the emissions from cars and motorbikes in the BAU scenario. Although emissions per $\mathrm{km}$ are higher for cars than for motorbikes $(200 \mathrm{gCO} / \mathrm{km}$ for car and 83 $g \mathrm{CO}_{2} / \mathrm{km}$ for motorbike, respectively), the total emissions from motorbikes are significantly higher than the emissions from cars due to the higher share of the motorbike mode. An important observation is that the NMHC from motorbike is approximately $95 \%$ of the total NMHC because - in contrast to other pollutants - motorbikes produce significantly

\footnotetext{
${ }^{14}$ For the Patna scenario, the Handbook Emission Factors for Road Transport (HBEFA; http://www. hbefa.net) version 3.2 is used. For motorbikes, it does not provide (a) the cold start emissions and (b) PM emissions. Thus, PM emissions are not shown in the analysis.
} 


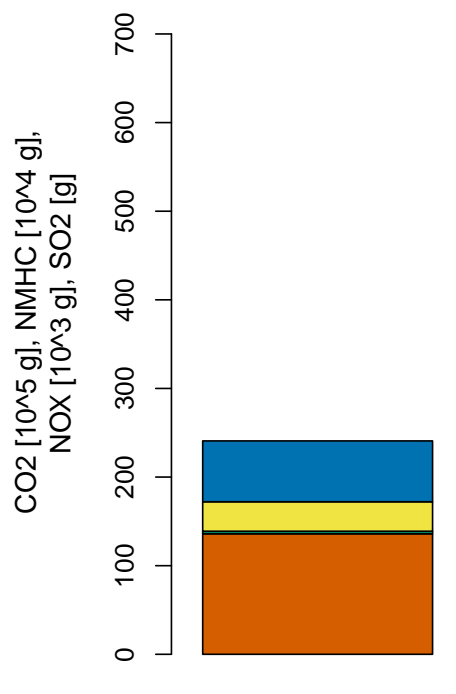

car

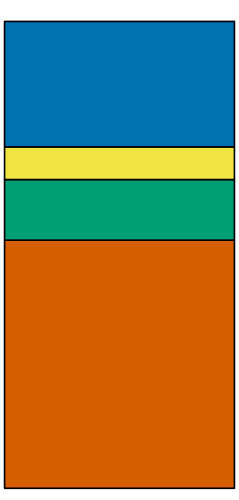

motorbike

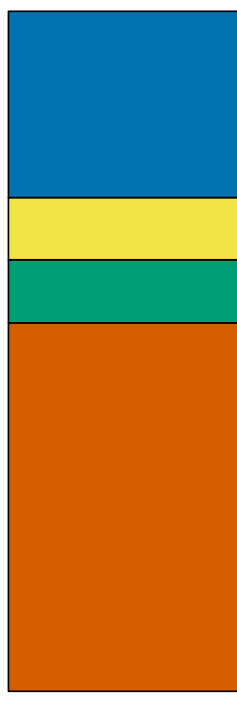

total

\section{$\square$ SO2 $\square$ NOX $\square$ NMHC $\square \mathrm{CO} 2$}

Figure 6: Absolute emissions for Patna BAU scenario.

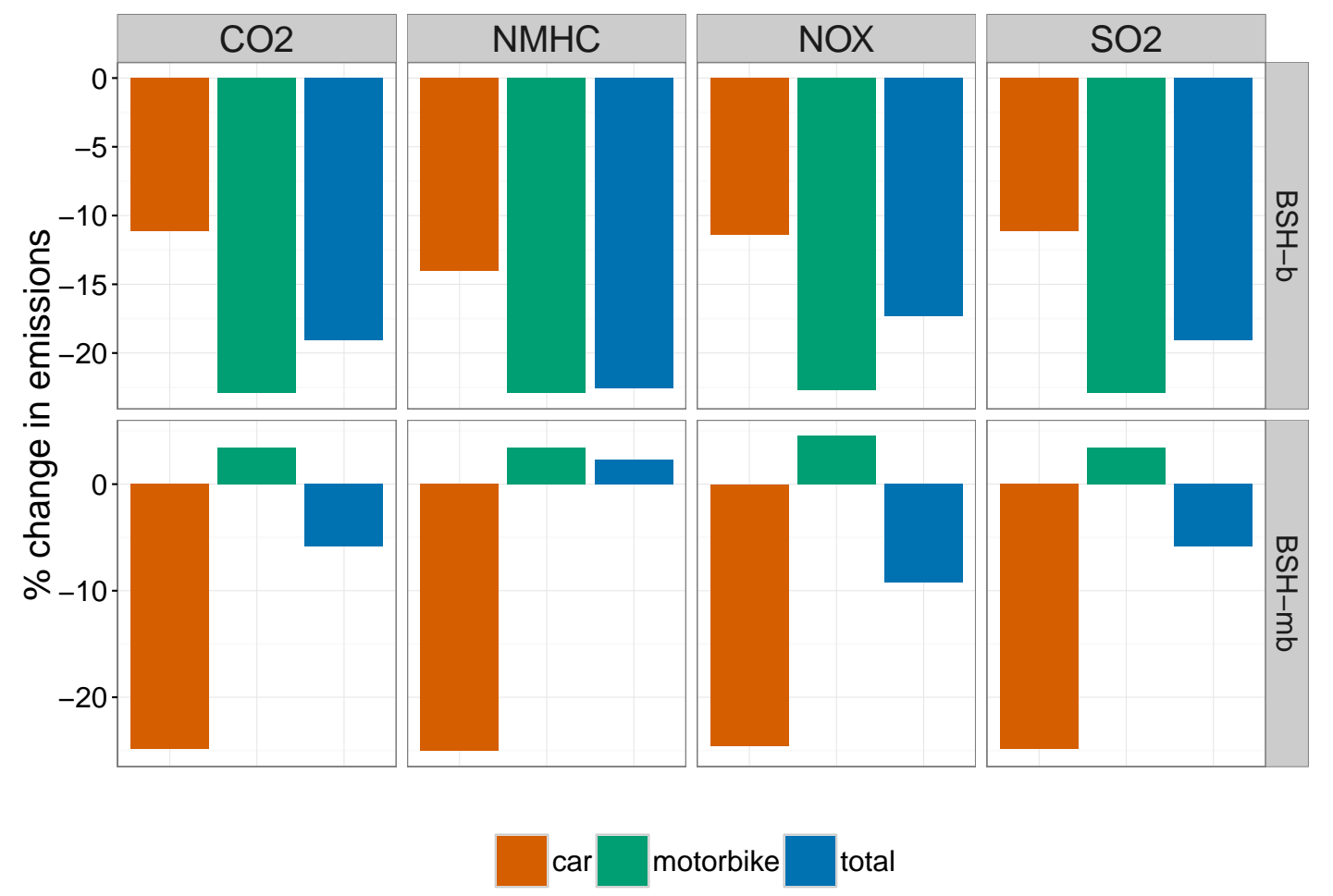

Figure 7: Changes in emissions (in \%) in the BSH-b and BSH-mb scenarios with respect to the BAU scenario. 
higher NMHC emissions than cars. ${ }^{15}$ The estimated emissions from cars and motorbikes $(0.49 \mathrm{gNO} / \mathrm{km}$ and $0.11 \mathrm{gNO} / \mathrm{km}$, respectively) are in line with the literature (Goel and Guttikunda, 2015).

\subsubsection{Changes in emissions for policy measures}

The changes in emissions for the two policy scenarios (BSH-b and BSH-mb) are shown in Fig. 7 relative to the business as usual (BAU) scenario. For the BSH-b scenario, all emissions are decreased significantly. This is a positive effect of higher bicycle share and lower motorized traffic (see Tab. 4). Further, in the BSH-mb scenario, a significant reduction in emissions for the car mode is observed. However, the increase in the share of motorbike yields an increase in the emissions for motorbike. Interestingly, total emissions are still lower than in the BAU scenario except NMHC. The share of NMHC emissions from motorbikes is approximately $95 \%$ in the BAU scenario and an increase in the share of motorbike in the BSH-mb scenario increases total NMHC emissions. Kickhöfer et al. (2018) also report an increase in NMHC emissions while pricing emissions for a real-world case study of Munich, Germany. In presence of sunlight, $N O_{x}$ and NMHC contribute to the creation of Ozone (National Research Council, 1991) and high amounts of groundlevel Ozone are harmful to respiratory systems of people/animals and to crops. Thus, an increase in NMHC emissions is a severe problems, especially if ground-level Ozone is already a problem.

To summarize this, the BSH-b policy measure reduces the emissions by a significantly higher share of the bicycle mode and lower share of motorized vehicles. In the BSH-mb scenario, the increase in the share of motorbike increases the emissions from motorbike, but the overall emissions decreases with the exception of NMHC emissions.

\subsubsection{Spatial distribution}

Fig. 8 shows the spatial distribution of $\mathrm{NO}_{2}$ emissions. ${ }^{16}$ Fig. 8 a shows the absolute emissions (in g) in the BAU scenario. The emissions on all major streets and "Gandhi Setu" are high. Figs. 8b and 8c show the change in $\mathrm{NO}_{2}$ emissions with respect to the BAU scenario for the BSH-b and the BSH-mb policy scenarios, respectively. An increase in emissions is indicated by red hexagons, a decrease in emissions is indicated by green hexagons, while white hexagons denote minor changes in $\mathrm{NO}_{2}$ emissions. It can be observed that the emissions on most portions of major roads decrease. This is an effect of the decrease in the share of motorized vehicles. The decrease in $\mathrm{NO}_{2}$ emissions on major arterials is more significant in the BSH-mb scenario due to capacity relief (dark green hexagons). In the BSH-mb scenario, a significant increase in emissions on the bicycle superhighway can be observed. This is the result of allowing motorbikes on the bicycle superhighway. The BSH-b policy measure reduces emissions significantly (approximately $18 \%$; see Fig. 7), mainly from inner city roads. In contrast to this, the BSH-mb policy reduces total emissions by only about $5 \%$ (see Fig. 7), and increases the emissions in the

15 The NMHC emissions from 2-stroke motorcycles are significantly higher than those of 4-stroke motorcycles (Tsai et al., 2000). Therefore, it is likely that the motorbike emissions are underestimated in this study.

${ }^{16}$ Similar to a previous study (Agarwal and Kickhöfer, 2016), for illustration purposes, the graphic only shows $\mathrm{NO}_{2}$. For the visual presentation, a Gaussian distance weighting function is used to smooth emissions. Uniform hexagonal cells of size $100 \mathrm{~m}$ are used for this purpose. The smoothing radius is assumed to be $100 \mathrm{~m}$. In contrast to Kickhöfer (2014), who assume the emissions at the centre of the link, the emissions are linearly distributed on the link. For more information on the exact visualization procedure, please refer to Appendix A in Agarwal (2017). 


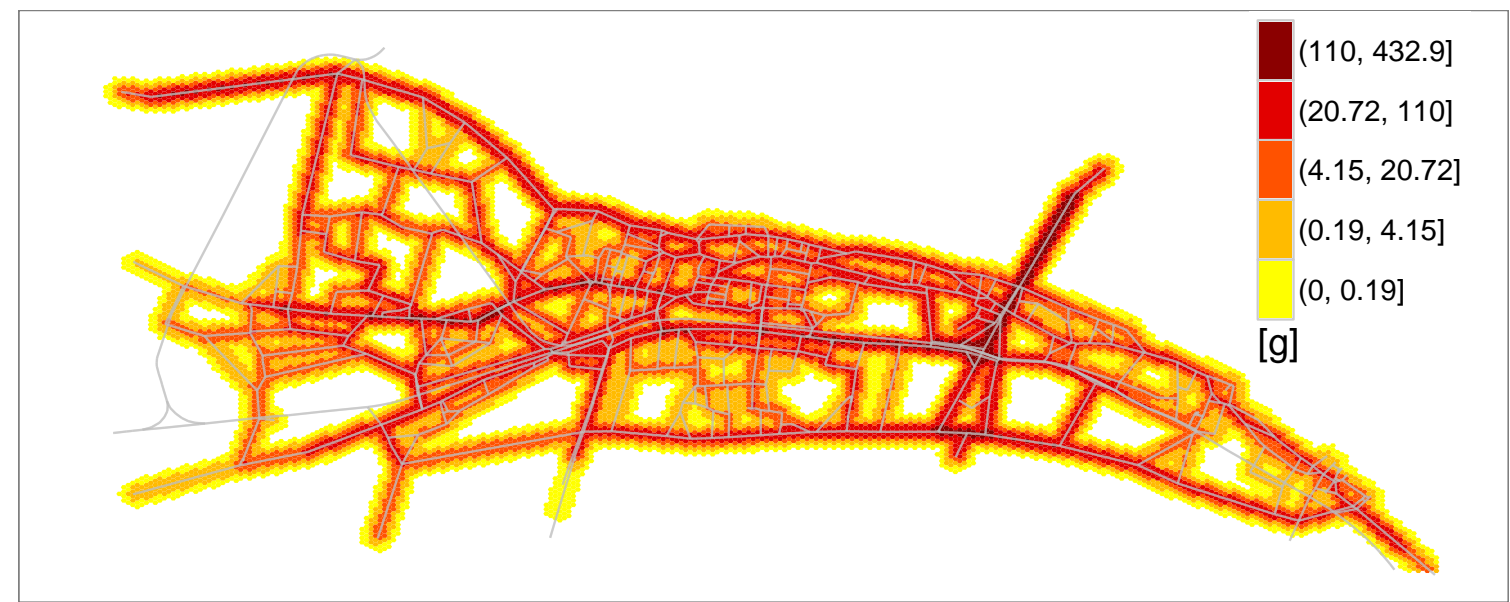

(a) Absolute emissions in the BAU scenario.

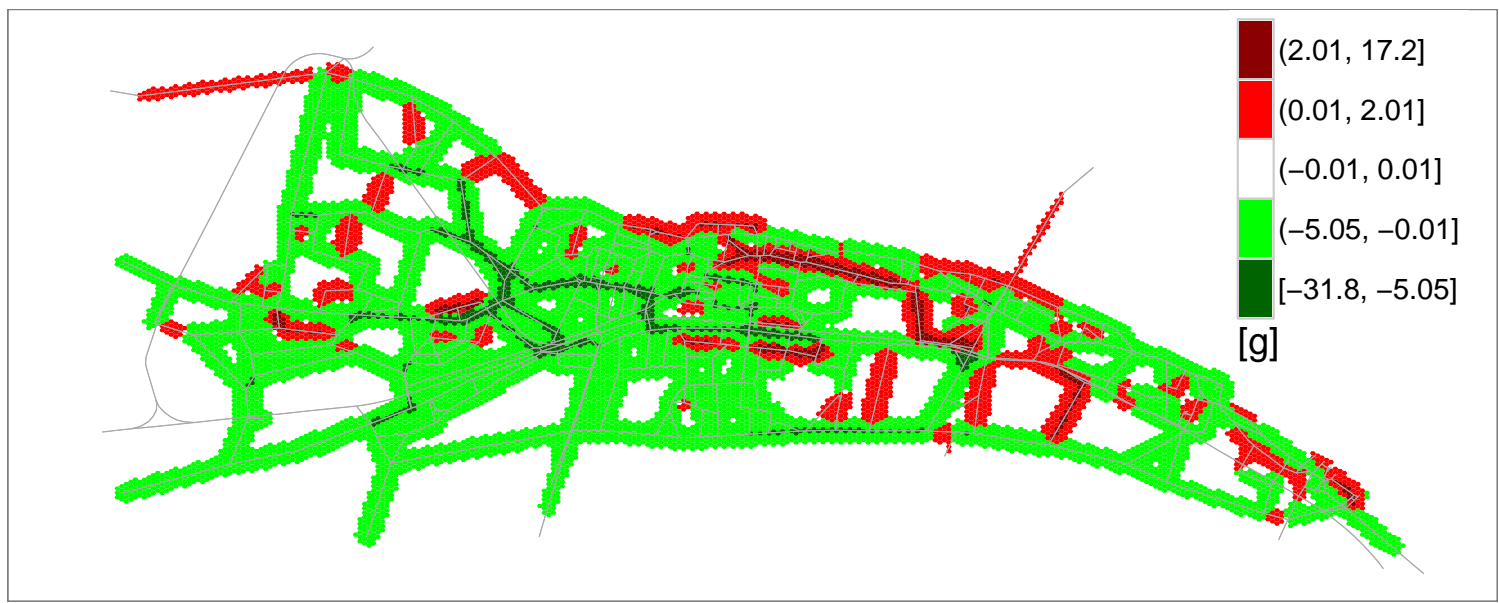

(b) Change in emissions in the BSH-b scenario.

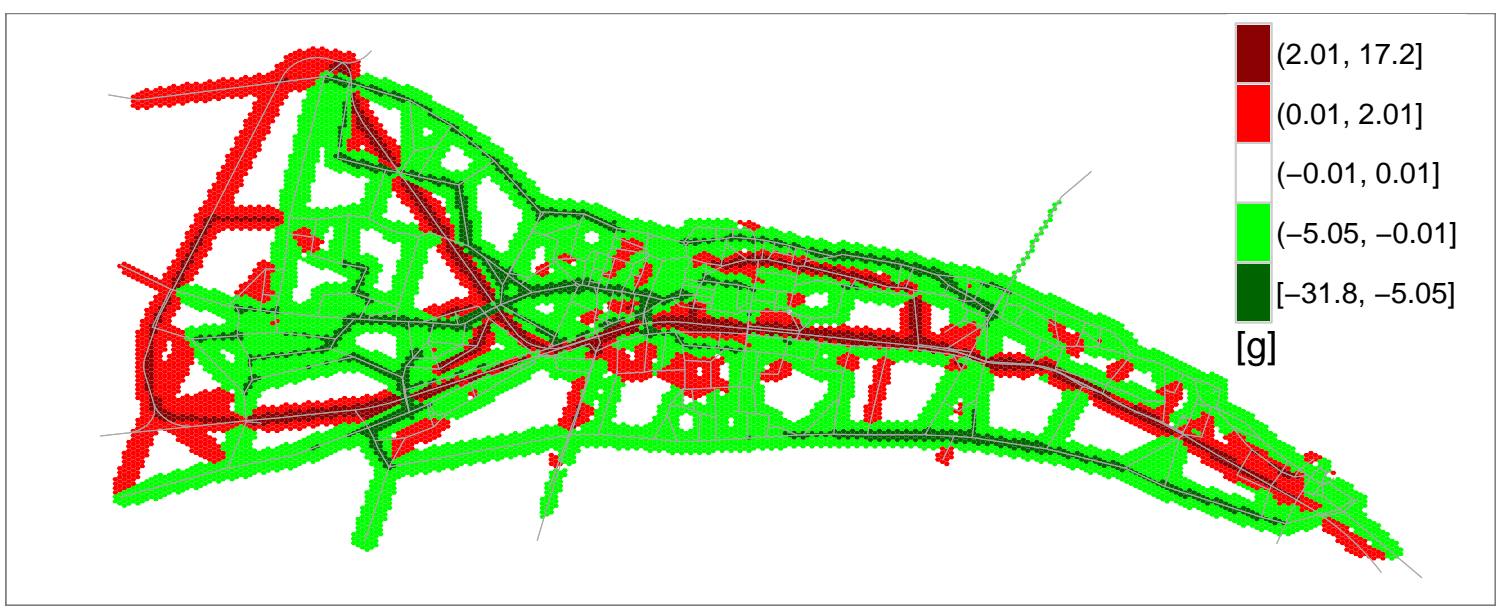

(c) Change in emissions in the BSH-mb scenario.

Figure 8: Absolute $\mathrm{NO}_{2}$ emissions (in g) in the BAU scenario and changes in emissions (in g) in the $\mathrm{BSH}-\mathrm{b}$ and BSH-mb policy scenarios. The values are scaled to the full population.

inner city, which is undesirable. It directs to impose strict policy measures to reserve the superhighway for bicycles. 


\subsection{Accessibilities}

\subsubsection{Computation approach}

As pointed out in Sec. 1.4, it is a goal of transport and city-planning policies to increase accessibility. Accessibility can be captured quantitatively and be used as a comprehensive and efficient planning instrument (Ziemke et al., 2017). In contrast to traditional planning tools, which are mostly based on travel alone (like measuring and monetizing changes in travel times, highway levels of service, or delays), the concept of accessibility is more strongly focused on the actual needs of individuals and households, i.e. the ease to reach locations to fulfill needs. As such, accessibility constitutes a holistic measure that, at least, consist of two components, a land-use (or activity) component and a transport component: The land-use component reflects the spatial distribution of opportunities and is characterized by both the amount and the location of different types of activity facilities. The transport component reflects the ease of travel between locations. Accessibility, i.e. the interplay of land use and transport, determines how well needs of individuals for certain services can be fulfilled.

In MATSim (cf. Sec. 3), accessibilities can be computed in an integrated way based on observations of the transport simulation, in particular travel utilities that trip-makers perceive when travelling on the network at a specific time-of-day. Typically, the logsum term, which has an econometric interpretation as the expected maximum utility (EMU) that can be obtained at a location $i$ from opportunities at other locations $j$, is applied. Accordingly, the accessibility $A_{i}$ of a location $i$ is computed as

$$
A_{i}=\ln \sum_{j} e^{-C_{i j}},
$$

where $j$ is an opportunity somewhere in the study area and $C_{i j}$ is the generalized cost of travel from $i$ to $j .{ }^{17}$ The $C_{i j}$ terms are computed based on the utilities of travelling as they were calibrated in the travel model (cf. Eq. (1)) plus the marginal utility of time as a resource (opportunity cost of time). As such, Eq. (4) does not require a scale parameter $(\mu)$ because we assume the utilities of Eq. (1) to be correct estimates for the choice situation under consideration.

Note that each opportunity $j$ is, indeed, an individual facility. Accordingly, there is no need to describe any sort of zones (e.g. by counting the numbers of opportunities within such zones). This simplifies the mathematical form of Eq. (4) and, at the same time, avoids unnecessary loss of accuracy by spatial aggregation. Further, it is assumed that each opportunity has the same attractiveness. Therefore, the utility impact perceived at location $i$ by an opportunity at $j$ is simply determined by the cost of travelling between $i$ and $j$.

The use of the logsum term renders distance cut-offs, which other measures of accessibility (e.g. isochrone-based measures) require, unnecessary. Opportunities far away from location $i$ have, by definition, a low impact on the accessibility score of location $i$, converging to zero with increasing distance.

\subsubsection{Changes in accessibilities for policy measures}

To evaluate the effects of the proposed bicycle superhighway, accessibilities to education facilities are computed. Education facilities are chosen because such facilities

17 Please refer to Ziemke et al. (2017, in particular, Section 3.1) for a more detailed mathematical justification of the formula as well as for technicalities of the computation of accessibilities within the MATSim transport simulation framework. 


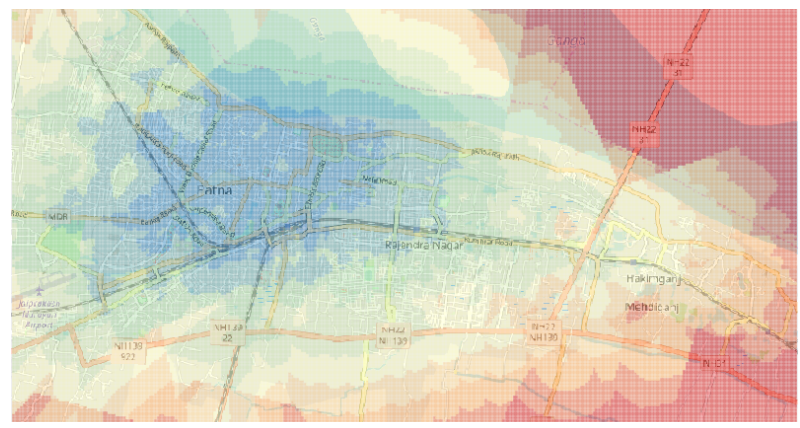

(a) Accessibilities in BAU scenario.

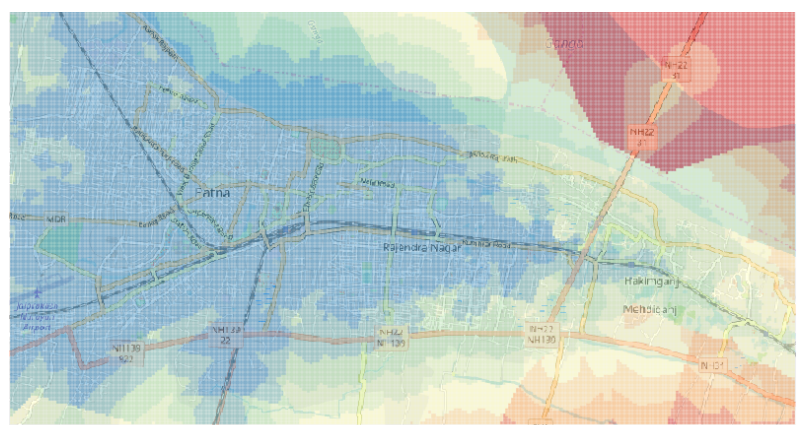

(b) Accessibilities in BSH-b scenario.

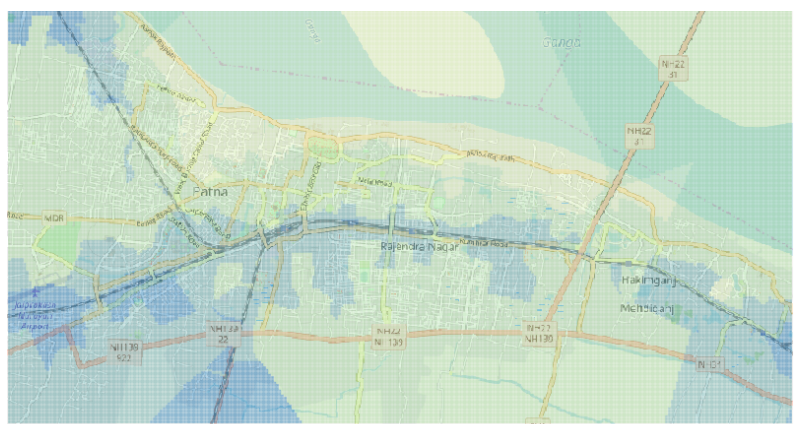

(c) Accessibility improvements in BSH-b scenario over BAU scanerio.

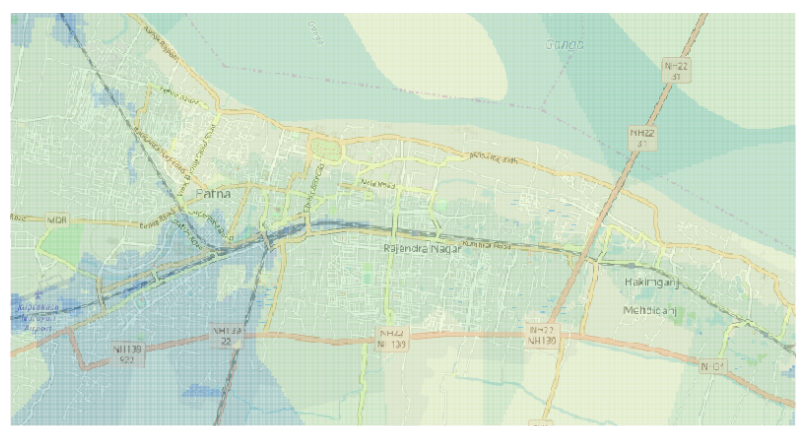

(e) Accessibility improvements in BSH-mb scenario over BAU scenario.

Figure 9: Accessibilities of education facilities by bicycle in BAU, BSH-b, and BSH-mb scenarios and accessibility changes between scenarios. Red colours denote low accessibilities (or, in comparative plots, an accessibility decrease), while blue colours denote high accessibilities (or, in comparative plots, an accessibility increase). Background map: (C)OpenStreetMap contributors (http://www.openstreetmap.org). 
are relevant for almost all socio-economic groups of the population. Data on locations and types of facilities are retrieved from OpenStreetMap (OSM) following the approach described by Ziemke et al. (2017).

Fig. 9 shows the accessibilities of education facilities by bicycle in the BAU, BSH-b and BSH-mb scenarios as well as corresponding accessibility changes in the BSH-b and BSH-mb scenarios with respect to the BAU scenario.

Notably, not only infrastructure-based changes between the scenarios, but also trafficstate-related effects are taken into account - reflecting the true quality of mobility that a trip-maker perceives. In particular, this enables to compare the BSH-b and BSH-mb scenarios, which are based on the same infrastructure (i.e. with the new bicycle superhighway), but can be assumed to differ in traffic properties as in the BSH-mb motorbikes are allowed to travel on the proposed bicycle superhighway, which is not permitted in the BSH-b policy scenario.

Fig. 9a depicts the accessibilities to education faculties by bicycle in the BAU scenario. It can be seen that accessibilities are the highest in the western central part of the city (depicted in blue colours).

Fig. 9b shows accessibilities to education facilities in the BSH-b scenario, while Fig. 9c depicts the changes in accessibilities of education facilities for the BSH-b scenario with respect to the BAU scenario. It can be seen that accessibilities to education facilities for bicyclists have improved significantly. Areas of low education accessibility (red- and yellow-coloured areas) have become discernibly fewer, while more areas are associated with a good accessibility now. As can be seen in Fig. 9c, areas in the vicinity to the proposed bicycle superhighway (cf. Fig. 3) are most strongly positively affected. However, also areas away from the proposed new infrastructure benefit, highlighting the positive city-wide impact of the bicycle superhighway.

In Figs. 9d and 9e, it can be seen that in the policy scenario where motorbikes are allowed to travel on the bicycle superhighway (BSH-mb scenario) there is an increase in accessibilities as well. However, the increase is - compared to the BSH-b policy scenario - significantly reduced. This is caused by motorbike which increase traffic on the bicycle superhighway and, thus, slow down bicycles on that infrastructure, causing accessibilities to decrease as activity facilities can only be reached with higher travel effort. In line with results of previous analyses, it is therefore shown that the effectiveness of the bicycle superhighway is reduced in case motorbikes are also allowed to travel on it. Given the agent-based simulation, an analysis to quantify the improvements in the accessibilities for specific group (e.g. based on income ) is possible however it is beyond the scope of the present study.

\section{Discussion}

Potential for increase in bicycle share In this study a bicycle superhighway is proposed for Patna, India. In this, car mode is mainly used by high to middle income users and motorbike is by middle-to-low income users. Bicycle, PT and walk modes are used by low income households which are captive to these modes. Under the assumption that bicycle is two times faster than before and efforts to ride a bicycle is reduced to half, the share of bicycle increases to $44 \%$ up from $32.5 \%$. From Tab. 5 a and Tab. 5b, it can be observed that $14 \%$ of car users, $30 \%$ of motorcyclists, $35 \%$ of PT riders and $12 \%$ walkers switch to bicycle mode. This indicates that increase in bicycle share is not triggered by economic-barriers only, rather it has become a more attractive travel mode not only to low income households but also to middle-to-high income groups. To verify this, increase 
Table 7: Increase in number of bicycle trips for different income classes

\begin{tabular}{l|rrrrrr}
\hline income class [USD] & 8 & 11 & 30 & 60 & 94 & 300 \\
\hline \% change & $17.97 \%$ & $21.29 \%$ & $33.81 \%$ & $36.64 \%$ & $32.55 \%$ & $34.80 \%$ \\
\hline
\end{tabular}

in number of bicycle trips for different income classes are shown in Tab. 7. Though, the share of bicycle is already high (32\%; Tab. 4), a significant increase in bicycle share for all income classes can be observed.

In other words, a bicycle-friendly infrastructure has huge potential for increase in bicycle share even for the cities where bicycle share is already high. Presumably, this increase can be higher if existing bicycle share is low. However, the maximum increase in bicycle share can be constrained by the availability and attractiveness of other modes.

Reasons why the share does not become even higher are:

- There is heavy bicycle congestion in many areas, see Fig. 5f. Thus, the bicycle superhighway would have to be significantly wider in those areas to accommodate an even larger bicycle share.

- There are many walk trips which are not along the investigated bicycle superhighway. These would thus not benefit from the new infrastructure, and thus a change to bicycle is not attractive.

- There are some trips which are so long that a motorized mode remains preferable.

Sensitivity analysis As discussed in Sec. 1, choosing a bicycle mode depends on several factors such as distance, slope, turn frequency, traffic volume, traffic-mix, intersection control, on-street parking, discontinuities, roadside land-use, physical-segregation of bicycle track etc. Further, safety, comfort, convenience of riding are other top concerns for potential cyclists (Jain et al., 2010). The choice model in the present study does not account for all of these factors explicitly rather incorporate them using a simplified assumption. As described in Sec. 4.2.4, it is assumed that on every link of the bicycle superhighway, bicycles are two times faster than on existing network and the efforts to ride a bicycle are reduced to half. Let's call this as "bicycle riding comfort index". In this section, a sensitivity analysis for bicycle riding comfort index is performed. For no improvements, the index is unity. Similar to the policy scenarios in Sec. 4.2.4, a new simulation is set up for every bicycle riding comfort index.

Table 8: Sensitivity for bicycle riding comfort index in BSH-b scenario

\begin{tabular}{l|ccccccc}
\hline bicycle riding comfort index & 1 & 1.11 & 1.33 & 1.5 & 2 & 3 & 4 \\
\hline share of bicycle & $35.30 \%$ & $36.58 \%$ & $40.1 \%$ & $42.33 \%$ & $48.78 \%$ & $51.98 \%$ & $53.2 \%$ \\
\hline
\end{tabular}

From Tab. 8, it can be observed that with no improvement (index=1), there is little increase in the bicycle share. In other words, having a bicycle track along with the existing roads is less likely to have significant increase in bicycle share. Similar finding is also obtained by Broach et al. (2012). As expected, increase in the BSH improvement factor will increase the share of bicycle in BSH-b scenario i.e. higher speed and lesser efforts are the keys to make riding of bicycle more attractive to potential cyclists. 


\section{Conclusion}

Bicycle is an environmentally sustainable transport mode, which can be used as a main transport mode as well as a feeder to mass public transit systems. However, in many parts of the world, it is becoming unattractive due to insufficient and/or unplanned infrastructure. In this direction, this study proposed a physically segregated bicycle superhighway for an urban agglomeration, where the share of non-motorized transport modes is very high. The idea with this is to demonstrate the potential of the increase in overall bicycle share. An innovative algorithm was proposed to determine the optimum number and locations of connectors between the superhighway and the existing network, which can be used for other scenarios also. Household income plays a vital role in the decision making process of travellers, in particular in developing economies where many users are captive to cheaper alternatives. This, in turn, is likely to affects the outcome of the policy measures. Therefore, in this study, the income levels were integrated in the utility function of individual travellers.

To evaluate the impact of the bicycle superhighway, a case study of Patna, India was considered. The application of bicycle superhighway to Patna illustrated huge potential to increase in the bicycle ridership. Allowing only cyclists on the bicycle superhighway increased the bicycle share as much as $48 \%$. However, allowing motorbikes also on it, narrowed the increase in bicycle share to 44\%. A detailed mode-switcher analysis showed that captive users (walk, public transport) as well as other motorized transport mode (e.g. motorbike) users switched to bicycle mode. Further, a marginal mode-switch from car to bicycle was observed. This essentially featured the increased attractiveness for bicycle travel mode from low-middle income households.

This study has extended an emission modelling tool to estimate the vehicle- and time-dependent emissions under mixed traffic conditions. Total emissions decreased significantly if only bicycles are allowed on superhighway. Allowing motorbikes on the superhighway decreases overall emissions to a limited extent with an exception of NMHC emissions. An overall increase in NMHC emissions is observed in this case which can impose major challenges if ground-level Ozone is a problem. However, a spatial analysis exhibited that a bicycle superhighway reduces emissions significantly as long as motorbikes are restricted on it. This emphasized the requirements of strong law enforcements or other measures to restrict the usage of superhighway for bicycle and cycle-rickshaws only. A computation of accessibilities, a policy assessment tool that is oriented on the actual needs of individuals, showed positive effects of the proposed bicycle superhighway on the accessibility of education facilities. While areas that are located in the direct vicinity of the new bicycle superhighway experience the highest accessibility increase, areas away from the new infrastructure also benefit from it in terms of increased accessibility. These positive effects are reduced if motorbikes are allowed to travel on the bicycle superhighway. This demonstrates that it is very important that a infrastructure is not only constructed appropriately, but also its use must be defined in a reasonable way. Otherwise, the benefits it provides may be compromised.

This study made an attempt to show the potential of increase in the bicycle share which is important for a low carbon urban transport. Such insights are useful for agencies to make decisions regarding transport policies. However, along with provision of infrastructure, to increase the share of bicycle, significant efforts are required to change the negative or neutral perception of the travellers (Gatersleben and Appleton, 2007). For instance, a mandatory program in schools to promote the bicycle usages because children have higher positive perception about cycling than adults (Verma et al., 2016). Similarly, 
introduction of voluntary programs to train the adults, seniors, new residents, etc. is likely to accumulate more cyclists (Buehler et al., 2016; Pucher and Buehler, 2008).

\section{Acknowledgements}

The support given by DAAD (German Academic Exchange Service) to first author for his PhD studies at Technische Universität Berlin is greatly acknowledged. The authors are grateful to anonymous reviewers for their valuable comments. The responsibility of any remaining errors stays with the authors.

\section{References}

A. Agarwal. Mitigating negative transport externalities in industrialized and industrializing countries. PhD thesis, TU Berlin, Berlin, 2017.

A. Agarwal and B. Kickhöfer. The correlation of externalities in marginal cost pricing: lessons learned from a real-world case study. Transportation, 45(3):849-873, 2016. doi:10.1007/s11116-016-9753-z.

A. Agarwal and G. Lämmel. Modeling seepage behavior of smaller vehicles in mixed traffic conditions using an agent based simulation. Transp. in Dev. Econ., 2(2):1-12, 2016. doi:10.1007/s40890-016-0014-9.

A. Agarwal, M. Zilske, K.R. Rao, and K. Nagel. An elegant and computationally efficient approach for heterogeneous traffic modelling using agent based simulation. Procedia Computer Science, 52(C):962-967, 2015. ISSN 1877-0509. doi:10.1016/j.procs.2015.05.173.

A. Agarwal, G. Lämmel, and K. Nagel. Modelling of backward travelling holes in mixed traffic conditions. In Victor L. Knoop and Winnie Daamen, editors, Traffic and Granular Flow '15, chapter 53, pages 419-426. Springer International Publishing, Delft, NL, 1 edition, 2016. ISBN 978-3-319-33482-0. doi:10.1007/978-3-319-33482-0_53.

A. Agarwal, G. Lämmel, and K. Nagel. Incorporating within link dynamics in an agentbased computationally faster and scalable queue model. Transportmetrica A: Transport Science, 2017a. doi:10.1080/23249935.2017.1364802.

A. Agarwal, D. Ziemke, and K. Nagel. Calibration of choice model parameters in a transport scenario with heterogeneous traffic conditions and income dependency. VSP Working Paper 17-21, TU Berlin, Transport Systems Planning and Transport Telematics, 2017b. URL http://www.vsp.tu-berlin.de/publications.

P. Anderson and N. Geroliminis. Dynamic lane restrictions on congested arterials. In 94th Transportation Research Board Annual Meeting, number 15-1838, 2015.

M. G. Badami and M. Haider. An analysis of public bus transit performance in Indian cities. Transportation Research Part A: Policy and Practice, 41(10):961-981, 2007. doi:10.1016/j.tra.2007.06.002.

L. Bai, P. Liu, C.-Y. Chan, and Z. Li. Estimating level of service of mid-block bicycle lanes considering mixed traffic flow. Transportation Research Part A: Policy and Practice, 101:203-217, 2017. doi:10.1016/j.tra.2017.04.031. 
H. Bar-Gera. The fast lane to Tel-Aviv: high occupancy toll project with a pareto package. In 91st Transportation Research Board Annual Meeting, number 12-0712, 2012.

Paolo Beria. Effectiveness and monetary impact of Milan's road charge, one year after implementation. International Journal of Sustainable Transportation, 2015. doi:10.1080/15568318.2015.1083638.

J. Broach, J. Dill, and J. Gliebe. Where do cyclists ride? a route choice model developed with revealed preference GPS data. Transportation Research Part A: Policy and Practice, 46(10):1730-1740, 2012. doi:10.1016/j.tra.2012.07.005.

R. Buehler, J. Pucher, R. Gerike, and T. Götschi. Reducing car dependence in the heart of Europe: lessons from Germany, Austria, and Switzerland. Transport Reviews, 37(1): 4-28, 2016. doi:10.1080/01441647.2016.1177799.

G. Bugliarello. Urban sustainability: dilemmas, challenges and paradigms. Technology in Society, 28(1-2):19-26, 2006. doi:10.1016/j.techsoc.2005.10.018.

Hao Cai and Shaodong Xie. Traffic-related air pollution modeling during the 2008 Beijing Olympic games: the effects of an odd-even day traffic restriction scheme. Science of The Total Environment, 409(10):1935-1948, 2011. doi:10.1016/j.scitotenv.2011.01.025.

Census. Census of India 2011, 2011. http://www.censusindia.gov.in/.

N. Cetin, A. Burri, and K. Nagel. A large-scale agent-based traffic microsimulation based on queue model. 2003.

B. Cohen. Urbanization in developing countries: current trends, future projections, and key challenges for sustainability. Technology in Society, 28(1-2):63-80, 2006. doi:10.1016/j.techsoc.2005.10.005.

G. Flötteröd. Cadyts - A free calibration tool for dynamic traffic simulations. In Swiss Transport Research Conference, September 2009. http://www.strc.ch/conferences/ 2009/Floetteroed.pdf.

B. Gatersleben and K. M. Appleton. Contemplating cycling to work: attitudes and perceptions in different stages of change. Transportation Research Part A: Policy and Practice, 41(4):302-312, 2007. doi:10.1016/j.tra.2006.09.002.

C. Gawron. An iterative algorithm to determine the dynamic user equilibrium in a traffic simulation model. International Journal of Modern Physics C, 9(3):393-407, 1998.

R. Goel and S. Guttikunda. Evolution of on-road vehicle exhaust emissions in Delhi. Atmospheric Enivronment, 105:78-90, 2015. doi:10.1016/j.atmosenv.2015.01.045.

T. Goldman and R. Gorham. Sustainable urban transport: four innovative directions. Technology in Society, 28(1-2):261-273, 2006. doi:10.1016/j.techsoc.2005.10.007.

K. Gwilliam. Cities on the move: A world bank urban transport strategy review. Technical report, The World Bank, 2002.

J. Hood, E. Sall, and B. Charlton. A GPS-based bicycle route choice model for San Francisco, California. Transportation Letters, (3):63-75, 2011. 
A. Horni, K. Nagel, and K. W. Axhausen, editors. The Multi-Agent Transport Simulation MATSim. Ubiquity, London, 2016. doi:10.5334/baw. URL http://matsim.org/ the-book.

C. Howard and E. Burns. Cycling to work in Phoenix: route choice, travel behavior, and commuter characteristics. Transportation Research Record: Journal of the Transportation Research Board, 1773:39-46, January 2001. doi:10.3141/1773-05.

F. Hülsmann, R. Gerike, B. Kickhöfer, K. Nagel, and R. Luz. Towards a multi-agent based modeling approach for air pollutants in urban regions. In Conference on "Luftqualität an Straßen", pages 144-166. Bundesanstalt für Straßenwesen, FGSV Verlag GmbH, 2011. ISBN 978-3-941790-77-3. Also VSP WP 10-15, see http://www.vsp.tu-berlin.de/ publications.

IRC:SP:30. Manual on economic evaluation of highway projects in India. Indian Roads Congress, New Delhi, India, 2009.

P. L. Jacobsen, F. Racioppi, and H. Rutter. Who owns the roads? how motorised traffic discourages walking and bicycling. Injury Prevention, 15(6):369-373, 2009. doi:10.1136/ip.2009.022566.

H. Jain, G. Tiwari, and M. H. P. Zuidgeest. Evaluating bicyclists comfort and safety perception. In J. M. Viegas and R. Macario, editors, $12^{\text {th }}$ World Conference on Transport Research, pages 1-19. WCTR Society, 2010.

B. Kickhöfer. Economic Policy Appraisal and Heterogeneous Users. PhD thesis, TU Berlin, Berlin, 2014.

B. Kickhöfer, F. Hülsmann, R. Gerike, and K. Nagel. Rising car user costs: comparing aggregated and geo-spatial impacts on travel demand and air pollutant emissions. In T. Vanoutrive and A. Verhetsel, editors, Smart Transport Networks: Decision Making, Sustainability and Market structure, NECTAR Series on Transportation and Communications Networks Research, pages 180-207. Edward Elgar Publishing Ltd, 2013. ISBN 978-1-78254-832-4. doi:10.4337/9781782548331.00014.

B. Kickhöfer, A. Agarwal, and K. Nagel. Mind the price gap: how optimal emission pricing relates to the $\mathrm{EU} \mathrm{CO}_{2}$ reduction targets. International Journal of Sustainable Transportation, 2018. doi:10.1080/15568318.2018.1472321.

K. J. Krizek, A. El-Geneidy, and K. Thompson. A detailed analysis of how an urban trail system affects cyclists' travel. Transportation, 34(5):611-624, 2007. doi:10.1007/s11116007-9130-z.

C. V. P. Kumar, D. Baus, and B. Maitra. Modeling generalized cost of travel for rural bus users: a case study. Journal of Public Transportation, 7(2):59-72, 2004. doi:10.5038/2375-0901.7.2.4.

S. Law, F. Sakr, and M. Martinez. Measuring the changes in aggregate cycling patterns between 2003 and 2012 from a space syntax perspective. Behavioral Sciences, 4(3): 278-300, 2014. doi:10.3390/bs4030278.

K. Martens. Promoting bike-and-ride: the Dutch experience. Transportation Research Part A: Policy and Practice, 41(4):326-338, 2007. doi:10.1016/j.tra.2006.09.010. 
H. McClintock and J. Cleary. Cycle facilities and cyclists/ safety. Transport Policy, 3 (1-2):67-77, 1996. doi:10.1016/0967-070x(95)00017-k.

G. Menghini, N. Carrasco, N. Schüssler, and K.W. Axhausen. Route choice of cyclists in Zurich. Transportation Research Part A, 44:754-765, 2009.

N. Mueller, D. Rojas-Rueda, M. Salmon, D. Martinez, C. Brand, A. de Nazelle, R. Gerike, T. Gotschi, F. Iacorossi, L. Int Panis, S. Kahlmeier, E. Raser, and E. Stigell. Health impact assessment of cycling network expansions in european cities. Journal of Transport E Health, 5:S9-S10, 2017. doi:10.1016/j.jth.2017.05.287.

K. Nagel and G. Flötteröd. Agent-based traffic assignment: Going from trips to behavioural travelers. In R.M. Pendyala and C.R. Bhat, editors, Travel Behaviour Research in an Evolving World - Selected papers from the 12th international conference on travel behaviour research, pages 261-294. International Association for Travel Behaviour Research, 2012. ISBN 978-1-105-47378-4.

K. Nagel, B. Kickhöfer, A. Horni, and D. Charypar. A closer look at scoring. In A. Horni, K. Nagel, and K. W. Axhausen, editors, The Multi-Agent Transport Simulation MATSim, chapter 3. Ubiquity, London, 2016. doi:10.5334/baw. URL http: //matsim.org/the-book.

National Research Council. Rethinking the Ozone Problem in Urban and Regional Air Pollution, chapter VOCs and $\mathrm{NO}_{\mathrm{x}}$ : relationship to Ozone and associated pollutants, pages 163-186. The National Academies Press, Washington, DC., 1991. doi:10.17226/1889.

Marco Percoco. The effect of road pricing on traffic composition: Evidence from a natural experiment in Milan, Italy. Transport Policy, 31(0):55-60, 2014. ISSN 0967-070X. doi:10.1016/j.tranpol.2013.12.001.

T.J. Powell. The Transport System - Markets, Modes and Policies. PTRC, 2001.

John Pucher and Ralph Buehler. Making cycling irresistible: Lessons from the netherlands, denmark and germany. Transport Reviews, 28(4):495-528, 2008. doi:10.1080/01441640701806612. URL http://www.tandfonline.com/doi/abs/10.1080/ 01441640701806612 .

T.M. Rahul and A. Verma. Economic impact of non-motorized transportation in Indian cities. Research in Transportation Economics, 38(1):22-34, 2013. doi:10.1016/j.retrec.2012.05.005.

R. Rastogi. Promotion of non-motorized modes as a sustainable transportation option: policy and planning issues. Current Science, 100(09):1340-1348, 2011.

I.N. Sener, N. Eluru, and C.R. Bhat. An analysis of bicycle route choice preferences in Texas, US. Transportation, 36:511-539, 2009.

C. Standen, M. Crane, A. Collins, S. Greaves, and C. Rissel. Determinants of mode and route change following the opening of a new cycleway in Sydney, Australia. Journal of Transport \& Health, 4:255-266, March 2017. doi:10.1016/j.jth.2016.10.004. URL https://doi.org/10.1016/j.jth.2016.10.004. 
J. G. Su, M. Winters, M. Nunes, and M. Brauer. Designing a route planner to facilitate and promote cycling in metro vancouver, canada. Transportation Research Part A: Policy and Practice, 44(7):495-505, 2010. doi:10.1016/j.tra.2010.03.015.

TfL. Cycle superhighways, accessed Sep. 2017. URL https://tfl.gov.uk/modes/cycling/ routes-and-maps/cycle-superhighways.

N. Y. Tilahun, D. M. Levinson, and K. J. Krizek. Trails, lanes, or traffic: valuing bicycle facilities with an adaptive stated preference survey. Transportation Research Part A: Policy and Practice, 41(4):287-301, 2007. doi:10.1016/j.tra.2006.09.007.

G. Tiwari. Traffic segregation: a case for bus priority lanes with segregated cycle tracks case study Delhi. Workshop on Transportation, Landuse, and The Environment, Pune, 2001.

G. Tiwari, A. Arora, and H. Jain. Bicycling in asia. Technical report, Interface for Cycling Expertise (I-ce), The Netherlands, 2008.

G. Tiwari, D. Jain, and K. R. Rao. Impact of public transport and non-motorized transport infrastructure on travel mode shares, energy, emissions and safety: Case of Indian cities. Transportation Research Part D: Transport and Environment, 44:277-291, 2016. doi:10.1016/j.trd.2015.11.004.

TransCAD. TransCAD, transporation planning software, 2012. http://www.caliper.com/ tcovu.htm.

TRIPP, iTrans, and VKS. Comprehensive mobility plan for Patna urban agglomeration area. Technical report, Department of Urban Development. Government of Bihar, 2009.

Jiun-Horng Tsai, Yih-Chyun Hsu, Hung-Cheng Weng, Wen-Yinn Lin, and Fu-Tien Jeng. Air pollutant emission factors from new and in-use motorcycles. Atmospheric Environment, 34(28):4747-4754, 2000.

United Nations. World urbanization prospects : The 2014 revision, highlights. Technical Report ST/ESA/SER.A/352, Department of Economic and Social Affairs, Population Division, 2014.

M. Verma, T.M. Rahul, P. V. Reddy, and A. Verma. The factors influencing bicycling in the Bangalore city. Transportation Research Part A: Policy and Practice, 89:29-40, 2016. doi:10.1016/j.tra.2016.04.006.

M. Wardman, M. Tight, and M. Page. Factors influencing the propensity to cycle to work. Transportation Research Part A: Policy and Practice, 41(4):339-350, 2007. doi:10.1016/j.tra.2006.09.011.

WEC. Global transport scenarios 2050. Technical report, World Energy Council, 2011.

Yu Zhou, Ye Wu, Liu Yang, Lixin Fu, Kebin He, Shuxiao Wang, Jiming Hao, Jinchuan Chen, and Chunyan Li. The impact of transportation control measures on emission reductions during the 2008 Olympic games in Beijing, China. Atmospheric Environment, 44(3):285-293, 2010. doi:10.1016/j.atmosenv.2009.10.040. 
D. Ziemke, J. W. Joubert, and K. Nagel. Accessibility in a post-apartheid city: comparison of two approaches for accessibility computations. Networks and Spatial Economics, 908 2017. doi:10.1007/s11067-017-9360-3. 